\title{
Review of Cost Estimates for Uranium Recovery from Seawater
}

\author{
Harry Lindner, Erich Schneider \\ University of Texas, Austin, United States of America \\ hdl@utexas.edu \\ 513-600-5659
}

\section{Introduction}

Two factors which have driven countries to pursue uranium recovery from seawater are supply security and the possibility of future uranium scarcity/shortage leading to a need to develop breeder reactors. Securing an independent energy supply is a priority for many countries who countries seek to insure themselves against abuses in supply or price which could have severe economic, social, and safety implications. Traditional uranium sources come from terrestrial mines that are concentrated in a few countries including Kazakhstan, Australia, Niger, and Canada. That leaves many countries without their own source for uranium and requires them to rely on the international market, as has historically been the case for India and China (Cochran, et al. 2010). Perceptions of the possibility of a future uranium shortage extend back to the dawn of the nuclear power era. Through the 1980s, there remained a belief that there would be an international uranium shortage by the present day. One important pioneer of uranium from seawater technologies (M. Kanno 1984) noted that "some additional production based on the other resources than known conventional resources will be required by the turn of the century." Those perceptions have continued in modern times: one researcher noted that the uranium price peak of the late 2000s was motivated "at least in part, [by] the expectation, compounded by speculation, that there might be uranium shortages." (Cochran, et al. 2010) 
To resolve the security and scarcity uncertainties, many have concluded that it would be desirable to develop an unconventional source of uranium to which virtually any country might have access. One such source is seawater, which boasts 3.3 parts per billion concentration of uranium. The sources for uranium in seawater are freshwater runoff as well as dissolution from the seabed. The Earth's seawater contains about 4.5 billion tonnes of uranium, a supply around 1,000 times greater than the known terrestrial resource of conventional uranium. Uranium from seawater could power the world nuclear power fleet at current rates of uranium consumption for about 13,000 years - an effectively infinite supply. Conversely, the supply of uranium from terrestrial, conventional sources is known to be sufficient for around 80 years of current rates of uranium consumption even when accounting for increased demand due to nuclear power growth worldwide - growth largely led by China (OECD Nuclear Energy Agency and the International Atomic Energy Agency 2012). In addition, discovery of uranium resources has outpaced consumption of uranium and growth of the nuclear power industry (OECD Nuclear Energy Agency and the International Atomic Energy Agency 2012).

Uranium recovery from seawater has many challenges. The first is the low concentration of uranium in seawater. Given the low concentration, the extraction strategy must physically place a ligand or adsorbent material into contact with large volumes of water, or move large volumes of seawater into contact with an adsorber. The second challenge is that uranium exists as uranyl ions in seawater in carbonate complexes, $\mathrm{UO}_{2}\left(\mathrm{CO}_{3}\right)_{3}{ }^{-4}$, which are relatively stronger than many ligands. Other chemical design challenges are that the ligand must be efficient at extracting uranium at the $\mathrm{pH}$ of seawater and the ligand (and whole adsorbent) must be insoluble. Another challenge is uranium concentration in seawater is comparatively low compared to other ions in seawater. A ligand that adsorbs uranium is likely adsorbing many other ions that 
are far less valuable. Conversely, the ligand may adsorb some valuable co-products. Although, research has been unable to adsorb the other valuable ions in concentrations enough to be included in cost analyses.

Because of its practically infinite supply, uranium from seawater would serve as an economic backstop uranium resource (Heal 1976). The cost of producing a commodity from a backstop resource is an effective ceiling on the price of the commodity. The long-term certainty of price provides stability to markets. That certainty can be translated to lower interest rates for borrowing capital and thus lower costs. The infinite supply also solves the supply security concern for countries. Previous U.S. government responses to supply security were hedging risk by investing in costly breeder reactor research and development (Cochran, et al. 2010). The cost of mining seawater for uranium is currently and historically greater than the price of uranium from conventional sources. The study of uranium recovery from seawater dates to the 1960's and spans many countries. Yet the technology remains uncommercialized.

\section{HOW ION RECOVERY FROM SEAWATER WORKS}

Uranium exists as uranyl ions in seawater. The uranyl ion is electrostatically attached to carbonate to form the complex uranyl carbonate, $\mathrm{UO}_{2}\left(\mathrm{CO}_{3}\right)_{3}{ }^{-4}$. The complex moves around freely in seawater. When it comes into contact with the adsorbent's ligand, the ion can leave the carbonate for a better chemical fit with the ligand, if the ligand is properly designed. Finding a ligand with the high adsorption capacity $(\mathrm{g} \mathrm{U} / \mathrm{kg}$ adsorbent) and selectivity for uranium is a key step toward the practical and economic viability of uranium recovery from seawater.

The general methodology for recovering uranium or other valuable ions from seawater is to produce an adsorbent or ion adsorbing sponge, make seawater to come in 
contact with the adsorbent (often through mooring or pumping), wait for the adsorbent to recover uranium, elute the adsorbent to recover the product, and prepare the adsorbent for another use of recovering ions. 


\section{Literature Review: Costs and Methods for Uranium Recovery from Seawater}

This section reviews cost estimates for past and contemporary technologies for extracting uranium from seawater. This meta-analysis fills an important gap because similar reviews of seawater uranium technology costs (Davies 1964) (M. Kanno 1984) (Tamada 2009) are over 20 years old or incomplete. An up-to-date, complete survey of technology cost analyses will provide context for the analysis presented in this work.

Most technologies and processes for recovering uranium from seawater share a few distinct characteristics. First, the chemical ligand/method used to capture the uranyl ions (the ion that uranium forms in seawater) is a key driver of performance and ultimately cost. A ligand must successfully compete with the carbonate in the complex, $\mathrm{UO}_{2}\left(\mathrm{CO}_{3}\right)_{3}^{-4}$, that forms in seawater. The ligand plays a large part in determining the adsorption capacity and selectivity and are major determinants of the cost of recovering uranium from seawater. The ligand can be complicated to produce and/or made from specialty chemicals. Therefore, if the chemicals used in preparing and grafting the ligand are too costly, the system will not be economical even if adsorption capacity is high.

The ligand attaches to or is precipitated on a substrate. The substrates vary widely in composition and cost. The substrates are usually long chains of a particular molecule ranging from high density polyethylene to chitin. Other substrates include glass wool and loosely woven cotton fabric. The ligand - substrate combination is referred to as adsorbent.

Closely related to ligand chemistry, albeit less fully documented or understood, is the degree of grafting (DOG). This measure is typically defined as a ratio of the mass or molarity of chemical ligand to substrate. If the degree of grafting is too low, there is little ligand attached to the substrate and capacity will be poor. If the DOG is excessively 
high, on the other hand, binding sites may be masked by other ligand and capacity ceases to increase with DOG. The economics suffer given that expensive grafting chemicals are not used optimally.

After the adsorbent is produced, a mooring strategy must be devised to efficiently contact the adsorbent with seawater. Mooring strategies range from placing structures in the ocean (floating or on the seafloor) to utilizing tides, building lagoons to run water through adsorbent beds in a controlled fashion, attaching adsorbent to ship hulls or offshore platforms or wind turbines, to anchoring buoyant adsorbent on the seafloor. These systems can be broadly classified into those that involve pumping or otherwise inducing flow through the adsorbent and others that are passive and rely on currents, tides and local advection. The less energy intensive passive systems have proven to be more economical.

The length of campaign is the amount of time the adsorbent has been in contact with seawater. A longer campaign can increase the amount of uranium adsorbed, but the rate of adsorption decreases over time, as the saturation capacity is approached. The optimal length of campaign is dependent on mooring and deployment costs. It may also be related to the flow rate of seawater over the adsorbent. Some schemes have found a significant impact from this (M. Kanno 1984) while others have not (Tsouris, et al. 2012). Likewise, the adsorption kinetics are affected by water temperature, with higher temperatures generally promoting more rapid adsorption. The temperature effect is not well understood and past modeling and experimental work has been limited (Tsouris, et al. 2012).

After the adsorbent is eluted for the uranium product, it can be chemically prepared for re-entry into seawater for another mooring stage of uranium recovery. Reusing the adsorbent a number of times can greatly reduce the uranium production cost 
as the expensive adsorbent produces more uranium over its life cycle. On the other hand, there is generally a loss of uranium adsorption capacity each time the material is reused. The loss of capacity may be due to damage to the ligand during elution or from occupation of sites by ions that are adsorbed in addition to uranium. These ions may not be removed from the ligand during the elution step. If they have negligible economic value, they are termed fouling co-products. Fouling co-products for the amidoxime adsorbent include vanadium, lead, iron, and magnesium (Sugo, et al. 2001).

Potentially valuable co-products also exist and include many precious metals: molybdenum, gold, silver, platinum, and palladium. Most of these ions exist in seawater at much lower concentrations than uranium (Turekian 1968). Thus in any small scale adsorbent test, any small amount of positive co-product collected is so small that it may be difficult to measure with mass spectrometry techniques (Mayes 2012). Hence very limited data have been reported concerning uptake of potentially valuable co-products.

This section organizes methodologies and cost estimates chronologically. A summary table is provided at the end of the section. For each reviewed methodology, the table includes a recovery description, capacity, substrate, ligands, substrate structure, mooring strategies, adsorbent uses, degradation, and cost. All costs given in the reviewed documents are adjusted to year 2010 dollars using the Consumer Price Index (CPI) (U.S. Bureau of Labor Statistics 2014).

\section{URANIUM RECOVERY FROM SEAWATER IN 1960'S AND EARLIER}

British and Russian scientists independently confirmed that the predominant molecular ion that uranium forms in seawater is $\mathrm{UO}_{2}\left(\mathrm{CO}_{3}\right)_{3}{ }^{-4}$. (Davies 1964) Hence this carbonate was identified as the chemical competition for any ligand. Scientists also 
recognized the challenge of grafting the ligand to a solid insoluble substrate. In (Davies 1964), this substrate was assumed to be an organic resin matrix.

(Davies 1964) was inspired by uranium adsorption on rust (hydrated ferric oxide) to pursue inorganic adsorbents. He precipitated inorganic salts on glass wool and placed these into a glass column for testing. He also considered muslin, a durable woven cotton fabric. (Davies 1964) published an estimate of the cost of uranium recovery from seawater in 1964. He tested many ligands and substrates. The ligands included phosphonic acids, kojic acid, salicylic acid, amino-carboxylic acid, amino-phosphoric acid, and hydrous titanium oxide. A promising result came from resorcinol arsenic acid ( $1.010 \mathrm{~g} / \mathrm{kg}$ in 112 days from the dry $\mathrm{H}+$ form.) However, that material lost capacity with continued use as a hydrolytic attack degraded the carbon and arsenic bond (Gupta and Singh 2003). He noted lead naphthalene tetracarboxylate gave $1.074 \mathrm{mg} / \mathrm{g}$ in 35 days, but it was unstable in seawater as well as the sodium carbonate eluent. Davies thus based his cost estimate on hydrous titanium oxide precipitated on glass wool or muslin. He saw $0.26 \mathrm{~g} \mathrm{U} / \mathrm{kg}$ adsorbent for muslin in 7 days and $0.26 \mathrm{~g} / \mathrm{kg}$ for glass wool in 20 days. Hydrous titanium oxide would continue to be the main focus of research for the next two decades.

(Davies 1964) assumed the tidal drift of seawater would be sufficient for supply of fresh uranium-bearing seawater given the rate of extraction was not too high. His system involved upper and lower lagoons that were opened and closed by a series of gates and dams. The seawater would flow into the upper lagoon then into the lower in a controlled fashion. The lower would have packed adsorbent beds. An associated chemical plant would sit on-site near the lower lagoon. For a site producing 1,000 tonnes of uranium per year $\left(1,100\right.$ short tons of $\left.\mathrm{U}_{3} \mathrm{O}_{8}\right)$, he estimated the cost would be $\$ 204$ to $\$ 408$ per $\mathrm{kg} \mathrm{U}$ in 2010 dollars or $\$ 11-\$ 20$ per $\mathrm{lb}$ of $\mathrm{U}_{3} \mathrm{O}_{8}$ as published. It was unclear 
how Davis achieved the low cost, but it was likely a combination of a low cost of mooring and a low cost of materials as his adsorption capacity was in-line with other hydrous titanium oxide based adsorbents. He noted that his mooring system was analogous to the planned Passamaquody Tidal Power Project from the U.S. Army Corps of Engineers.

\section{0's AND 1980's}

Kanno (1984) published a review of cost estimations for uranium recovery from seawater, many of the adsorbents were theorized and their experiments were conducted in the 1970s. In his assessment, he assumed existing materials and capacities such as hydrous titanium oxide and its capacity. He explored various mooring schemes in which seawater would need to actively be pumped. Kanno approached the recovery by calculating the amount of seawater required to produce 990 tonnes of uranium per year. He calculated the amount of seawater needed given its concentration of $3.3 \mu \mathrm{g} U / \mathrm{L}$ of seawater (3.3 ppb) and assuming 100\% uranium extraction, to be $3 \times 10^{11} \mathrm{~m}^{3} / \mathrm{yr}$. It appears Kanno measured adsorption capacity as a recovery percentage, scaling water pumping requirements up from the amount of water needed given full recovery.

The early designs Kano assessed assumed pumping seawater through a fixed packed bed of hydrous titanium oxide adsorbent. The ligand exists as a precipitate and was prepared by sifting onto a mesh as discussed in (Yamashita, et al. 1980), yielding adsorption performance measured at $0.196 \mathrm{~g} \mathrm{U} / \mathrm{kg}$ adsorbent in 10 days. In his cost analysis, Kanno used the adsorbent 25 times with $0.1 \%$ capacity loss per use. The adsorbent was packed into beds, which are held in place at a seaside facility. The facility stretched 5.5 miles sitting on shore, parallel to the shoreline. Its 467 pumps pumped 80

$\mathrm{m}^{3}$ water / $\mathrm{s}$ through the $5.19 \times 10^{4}$ tonnes of adsorbent. The power requirement for the 
pumps was $67 \mathrm{x} 104 \mathrm{~kW}$. The system cost was reported as $\$ 868 / \mathrm{kg} \mathrm{U}$ in 1976 dollars or $\$ 3,300$ in 2010 dollars (M. Kanno 1981). (M. Kanno 1984) A second design employed larger pumps with a capacity of $500 \mathrm{~m}^{3} / \mathrm{s}$, around a $600 \%$ increase. The facility was redesigned to extend from the shore in the fashion of a breakwater. Figure 1 shows this facility. With the increased pumping capacity, the facility was shorted to 2.7 miles (4.3 $\mathrm{km}$ ) including the regeneration facility (used to prepare an eluted adsorbent for re-entry in seawater) and the number of pumps reduced to 60 . Using this system, the uranium production cost was estimated to be $\$ 580 / \mathrm{kg} \mathrm{U}$ in 1976 dollars or $\$ 2,200$ in 2010 dollars. (M. Kanno 1981) (M. Kanno 1984)

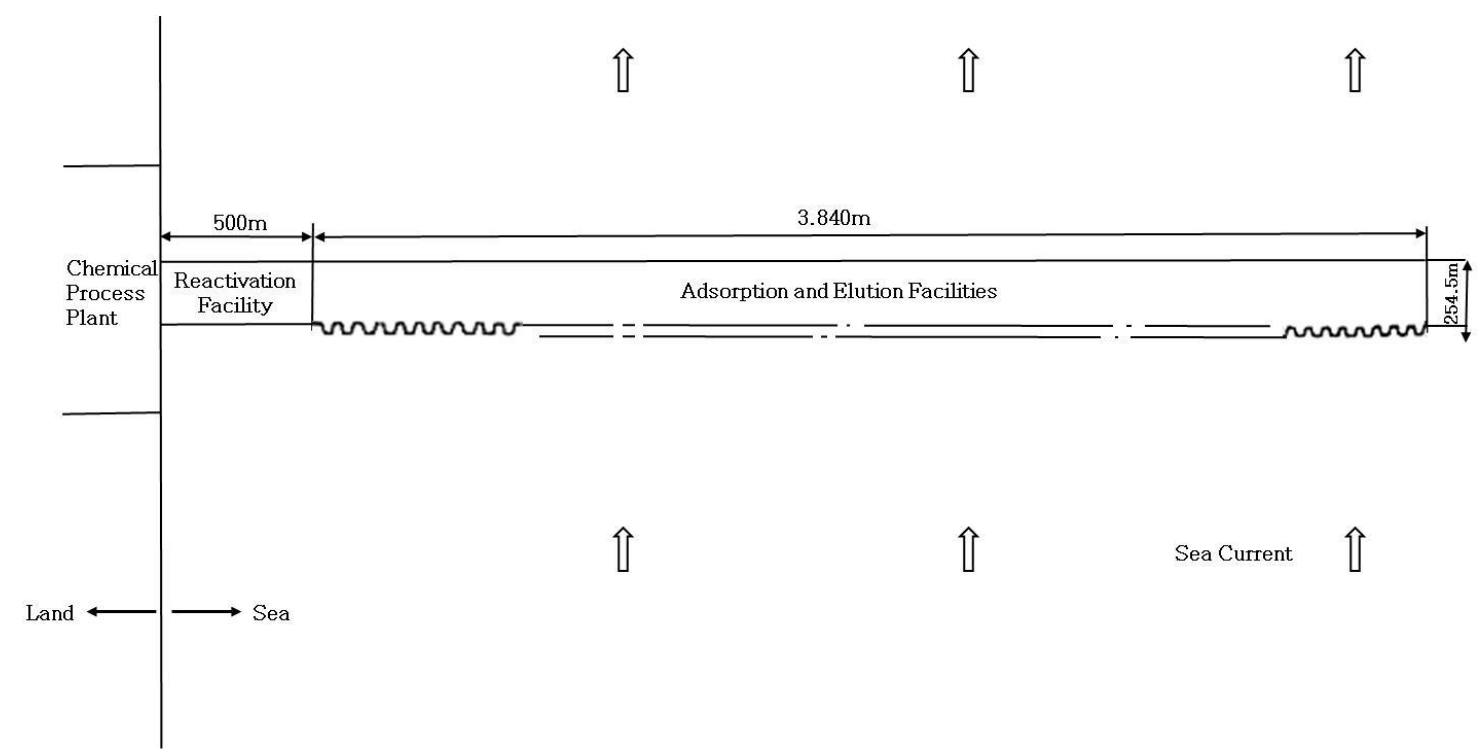

Figure 1. Early design of seawater processing facility (M. Kanno 1984)

Kanno presented a sensitivity analysis based on experimental data where he increased the adsorption recovery efficiency from $60 \%$ to $80 \%$ of uranium in the seawater and increased the uranium concentration in the eluate from $10 \mathrm{ppm}$ to $20 \mathrm{ppm}$ (eluate is the solution obtained from elution.) This allowed the facility size to be reduced 
by $1 \mathrm{~km}$ from $4.3 \mathrm{~km}$ and the number of pumps to be reduced by 20 from 60 . Kanno estimated the cost to be $\$ 420 / \mathrm{kg} \mathrm{U}$ in 1976 dollars or $\$ 1,600$ in 2010 dollars. (M. Kanno 1984)

Kanno also explored a concept that directly utilized sea currents by placing adsorbent 'units' on the seafloor (M. Kanno 1981). A unit consisted of $5 \mathrm{~m}$ x $5 \mathrm{~m}$ x $5 \mathrm{~m}$ adsorbent cubes stacked three cubes high in series, and parallel (Figure 2). The cubes were structures that held loosely packed beds of adsorbent that seawater would flow through. Kanno continued to use the hydrous titanium oxide adsorbent. The unit was placed in on the seafloor in flat, shallow waters. The reasoning appeared to be ease of mooring scheme where materials could easily be exchanged between the facility and shore. The unit dimensions were calculated to be $17.3 \mathrm{~m}$ in width, $45 \mathrm{~m}$ in height and 1.7 $\mathrm{km}$ in length (1 mile). 30 units were deemed necessary to adsorb 1,000 tonnes of $\mathrm{U}$ per year. Kanno estimated the cost of recovering uranium with this system to be $\$ 650 / \mathrm{kg} \mathrm{U}$ in 1976 dollars or $\$ 2,500$ in 2010 dollars. Kanno provided a sensitivity analysis where the 'units' were reconfigured into thin packed beds of adsorbent placed between two porous supporting plates. He estimated the cost to be $\$ 470 / \mathrm{kg}$ U in 1976 dollars or $\$ 1,750$ in 2010 dollars. (M. Kanno 1984)

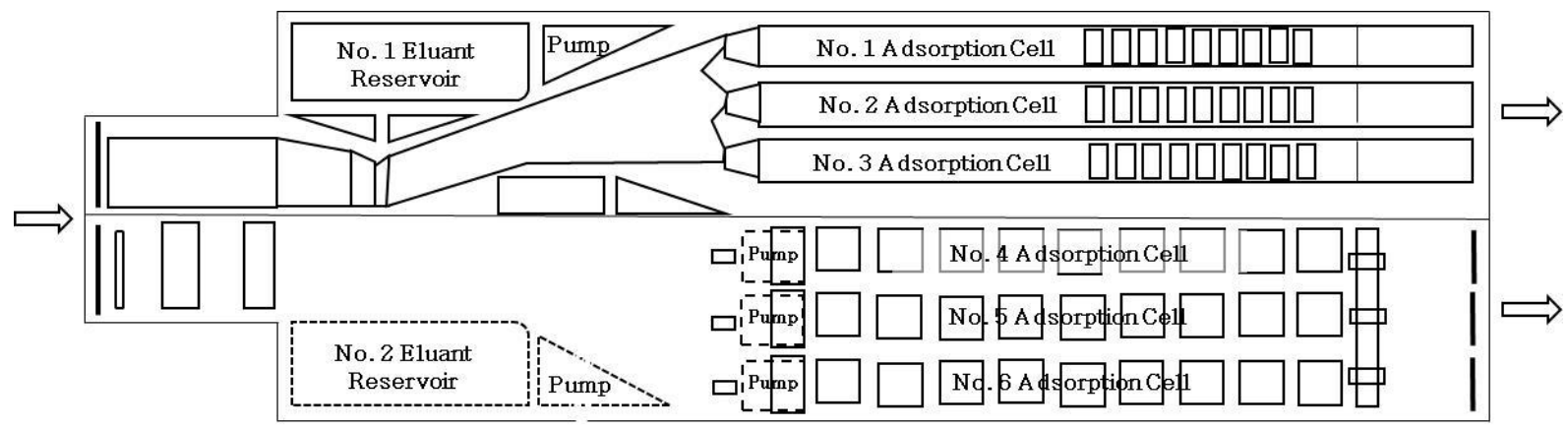

Figure 2. Design of a sea current utilizing 'unit'. (M. Kanno 1984) 
In summary, Kanno's work explored many mooring strategies utilizing the hydrous titanium oxide adsorbent. His cost analyses were affected by several assumptions regarding the capacity and durability of the material. For example, it was evident from subsequent work that the degradation per use $(0.1 \%)$ and the number of times the adsorbent can be used, 25, were overly optimistic. Another key assumption underlying his analyses was that the adsorbent would capture 60 or $80 \%$ of the uranium in a given mass of seawater. A simple mass balance based on measured uptake rates of less than $1 \mathrm{~g} \mathrm{U} / \mathrm{kg}$ ads over 10 to 20 days would show that the uranium recovery fraction was in fact orders of magnitude lower. Thus the pumping requirements in Kano's schemes are too small and the cost estimates unrealistically favorable.

An experimental plant using hydrous titanium oxide operated from 1981 to 1988 by Agency for Natural Resource and Energy, the Ministry of International Trade and Industry and Metal Mining Agency of Japan (Tamada 2009) The adsorption ability of the hydrous titanium oxide was reported at $0.1 \mathrm{~g} \mathrm{U} / \mathrm{kg}$ adsorbent, which was deemed not economically feasible. The Japanese team estimated that to be economically feasible, the adsorption capacity would need to increase by a factor of 10 (Tamada 2009. Hence the 1980's saw a move away from hydrous titanium oxide to polyacrylamidoxime adsorbents.

The Massachusetts Institute of Technology (MIT) team of Driscoll, Borzekowskim, Best, and others switched to an amidoxime ligand on acrylic based adsorbent because of its increased adsorption (Driscoll 1983). MIT also adopted a small diameter fiber or wool-like adsorbent or as opposed to particle beds because the beds were shown to reduce capacity (Varela 1983). This was likely due to water being unable to penetrate them as well. Driscoll observed that adsorption is the key factor in determining economic viability, and the packed bed concept reduced overall adsorption. 
(Borzekowski, Driscoll and Best 1982) used an amidoxime ligand on an acrylic and styrene based adsorbent to test adsorption in seawater with help from Woods Hole Oceanographic Institution. This appears to be one of the first amidoxime based tests. The longest campaign length they experimented with was 7 days. The highest adsorption capacity documented was $0.094 \mathrm{~g} \mathrm{U} / \mathrm{kg}$ ads with the acrylic amidoxime adsorbent. They compared this to $2.0-2.4 \mathrm{~g} / \mathrm{kg}$ for amidoxime adsorptions at 50 to 200 day campaign lengths reported from German and Japanese sources. They noted that in the 7 day trials, the adsorbent was far from its saturation capacity, which would be achieved with longer campaign lengths such as those used in the Japanese measurements. Vanadium and molybdenum were observed as potential co-products. In addition to the amidoxime, two biosorbers, Rhizopus Arrizus and Penicillium Chryzogenum, were tested and showed near zero uranium uptake. These biosorbers are fungi. The latter is the source for penicillin.

Driscoll published a cost estimate for the amidoxime-acrylic adsorbent that modeled a fixed-leg off-shore oil production platform with a submerged deck, shown in Figure 3 (Driscoll 1983). Each platform could produce 40 tonnes of uranium per year using pumps (low head, axial-flow). The adsorbent was a cylindrical roll of spinbonded acrylic amidoxime fiber sheet which was projected to have a loading rate of $700 \mathrm{ppm} / \mathrm{d}$ and a capacity of 5,000 ppm or $5 \mathrm{~g} \mathrm{U} / \mathrm{kg}$ ads. Driscoll published the cost to be $\$ 360 / \mathrm{kg}$ $\mathrm{U}$ in 1983 dollars or $\$ 800$ in 2010 dollars. Taking credit for marketable co-products, molybdenum and vanadium, the cost became $\$ 290$ / $\mathrm{kg}$ U in 1983 dollars or $\$ 630$ in 2010 dollars. (Driscoll 1983) (M. Kanno 1984) 


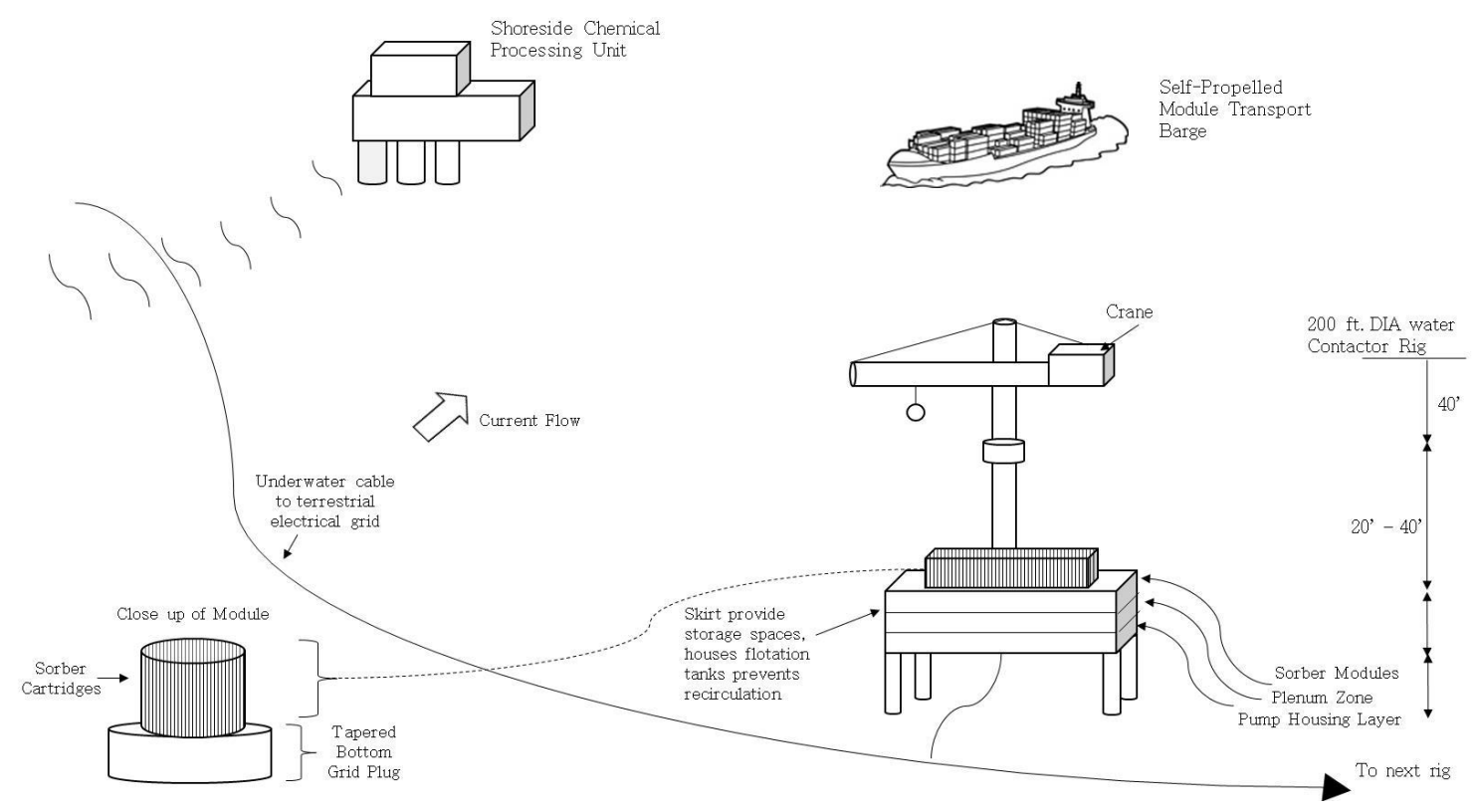

Figure 3. Mooring System with Platforms (Driscoll 1983)

Two large concerns arose with the previous systems: the assumption for adsorption capacity and the active pumping system. The adsorption capacity used to model cost was not observed experimentally in this study nor was it observed in any study (including the most recent analysis.) A related flaw is how the capacity number was theorized- using a linear relationship between capacity and time. That relationship was also not seen experimentally or in any other study. The more accurate representation of the relationship between adsorption rate and time is a logarithmic relationship where uptake rate is initially very large and then plateaus. The mooring system also actively pumped seawater. In retrospective analysis, the pumps may not have been necessary, but research using passive systems was not theorized until the 1990's as will be discussed in the following section.

Bitte of Uranerzbergbau Co. presented four different type concepts of floating structures using a polyacrylamidoxime resin adsorbent in fluidized beds. (Bitte, Keller 
and Ludwig 1983) Bitte assumed a linear adsorption of 20ppm per day $(0.02 \mathrm{~g} \mathrm{U} / \mathrm{kg}$ adsorbent) over 360 days, leading to a total uranium uptake of $7.2 \mathrm{~g} / \mathrm{kg} \mathrm{U}$. The concepts are summarized in the following illustrations:

- Self-propelled, semisubmersible catamaran concept (Figure 4)
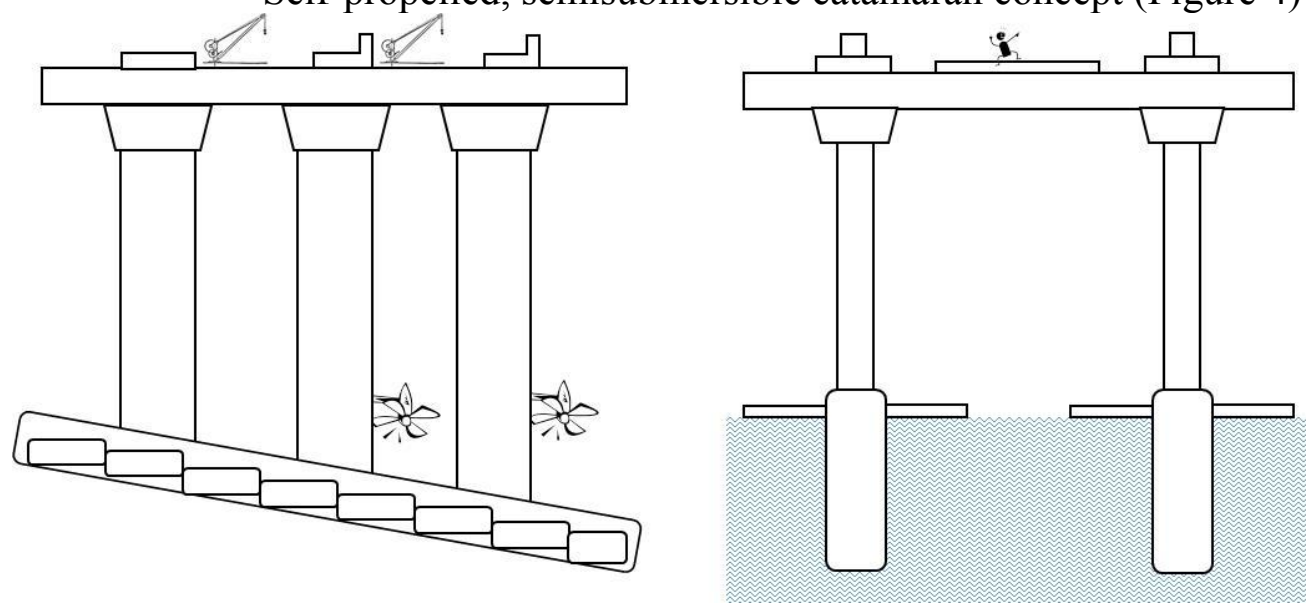

Figure 4. Self-propelled, semisubmersible catamaran concept (Bitte, Keller and Ludwig 1983)

- A moored semi-submersible catamaran concept (Figure 5)

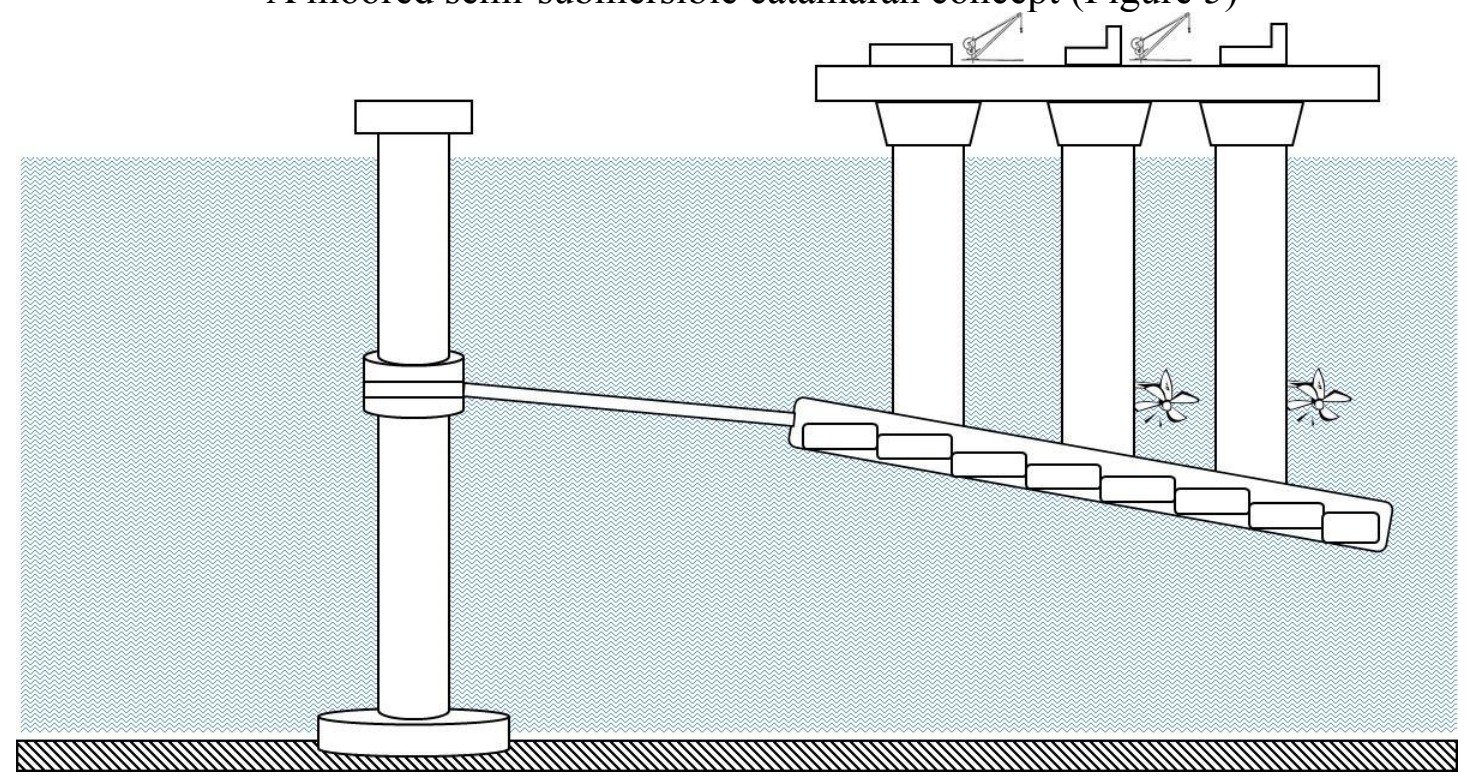


Figure 5. A moored semi-submersible catamaran concept (Bitte, Keller and Ludwig 1983)

- A ship concept with horizontal water intake (Figure 6)

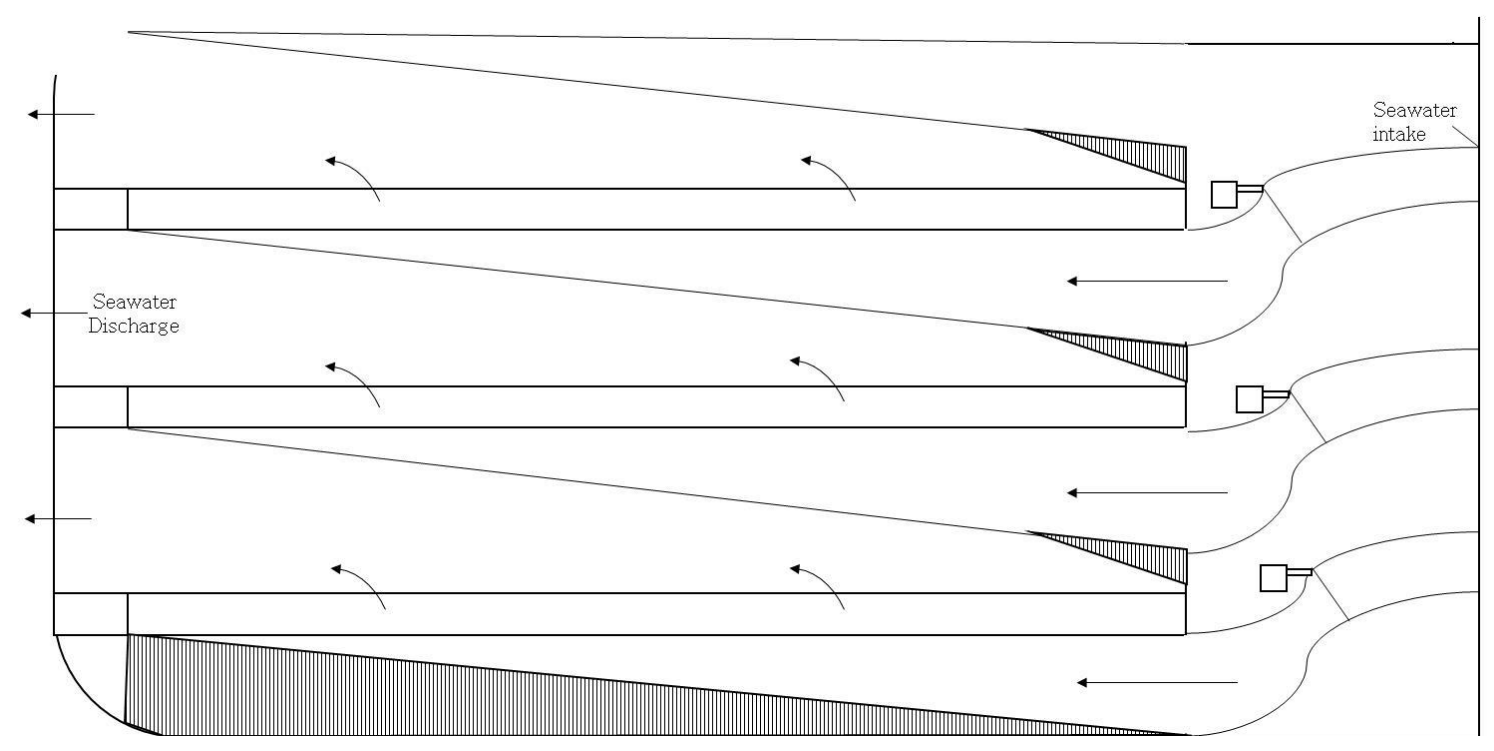

Figure 6. A ship concept with horizontal water intake (Bitte, Keller and Ludwig 1983)

- A ship concept with vertical water intake (Figure 7) 


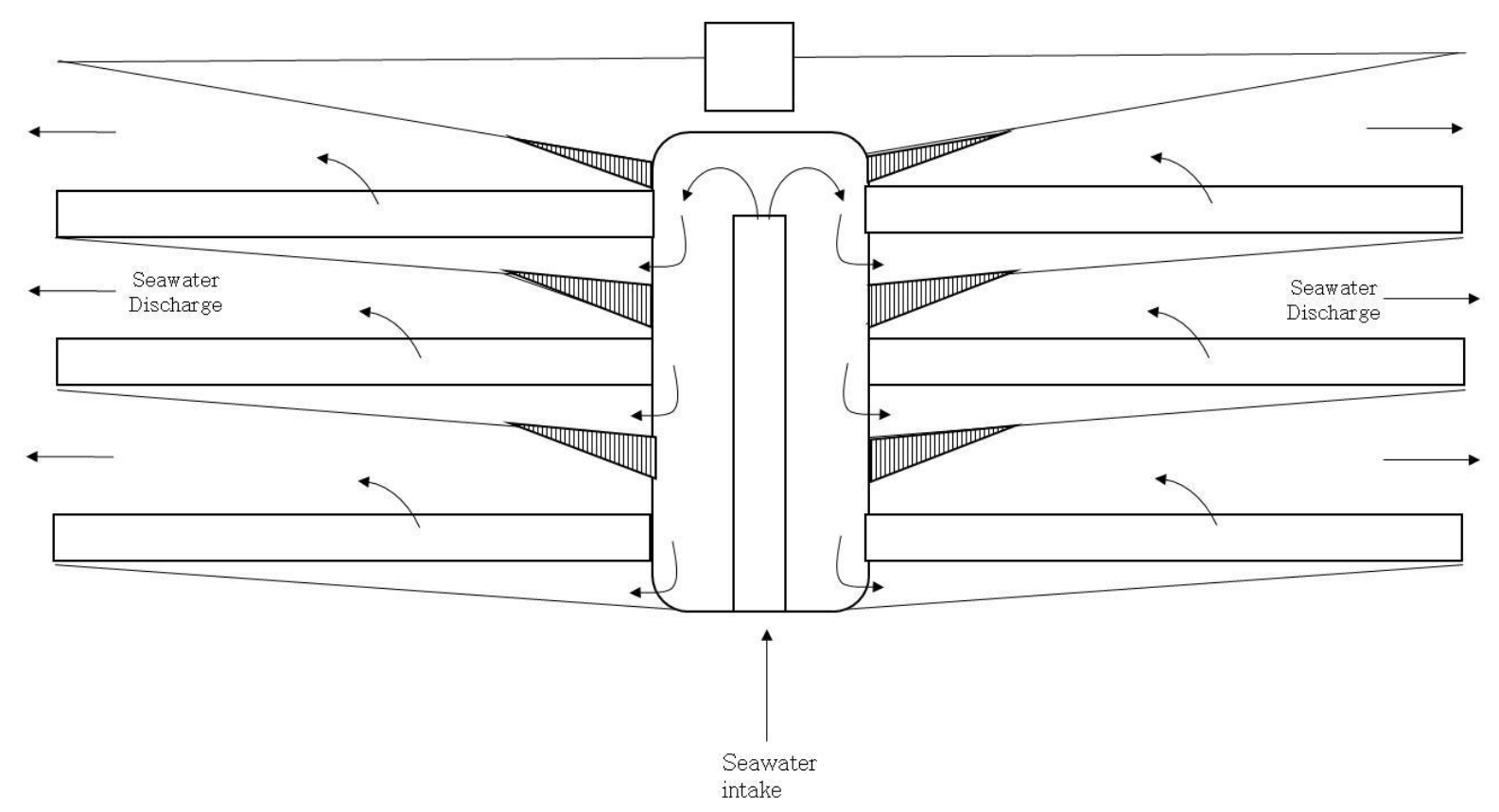

Figure 7. A ship concept with vertical water intake (Bitte, Keller and Ludwig 1983)

All of these schemes relied on forced convection using pumps. The lowest cost estimate was for the first scheme: $\$ 650$ / $\mathrm{kg} \mathrm{U}$ in 1983 dollars or $\$ 1,400$ in 2010 dollars. That was followed by the fourth, second, then third at a range of $\$ 1,900$ / $\mathrm{kg} U$ to $\$ 2,650$ / $\mathrm{kg}$ with the cost of steel as a major driver of the economics. Sensitivity analysis on increasing the number of uses of adsorbent from 10 to 25 and increasing the bed velocity reduced the cost to $\$ 130 / \mathrm{kg} \mathrm{U}$ in 1983 dollars or $\$ 285$ in 2010 dollars. The Bitte cost estimate assumed a time-invariant adsorption rate, which was not the behavior that was observed in marine tests. Neither this assumption nor the value used for the capacity, 7.2 $\mathrm{g} \mathrm{U} / \mathrm{kg}$ ads, at 360 days of campaign length, were backed by experimentation.

Koske of the University of Kiel cooperated with GKSS Research Center, (Gesellschaft zur Förderung der Kernenergie in Schiffbau und Schiffstechnik, German: Society for the Promotion of the Nuclear Energy in Shipbuilding and Naval Technology) 
Geesthachto, Germany to create a loop system, using gravity and suction to move water through a structure. Hence the system was free from the cost of pumping water. Koske was wished to move away from fixed and fluidized beds of adsorbent given the fouling and clogging issues that had arisen during experimentation. The adsorbent used in this scheme was granular and entrained in the flowing water. In this closed loop scheme, Koske defined the adsorbent performance as the ratio of uranium recovered to total uranium passing through the structure. With a structure size of $200 \mathrm{~m}$ in length and $40 \mathrm{~m}$ in width and the gross tonnage of 58,384 GRT, a single unit could produce 20 tonnes of uranium a year. Figure 8 depicts this scheme. Varying the seawater flow rate from $42 \sim 12.5 \mathrm{~cm} / \mathrm{s}$, Koske estimated the cost to be $\$ 450$ to $\$ 870 / \mathrm{kg}$ U in 1983 dollars or $\$ 970$ to $\$ 1,900$ in 2010 dollars (M. Kanno 1984).

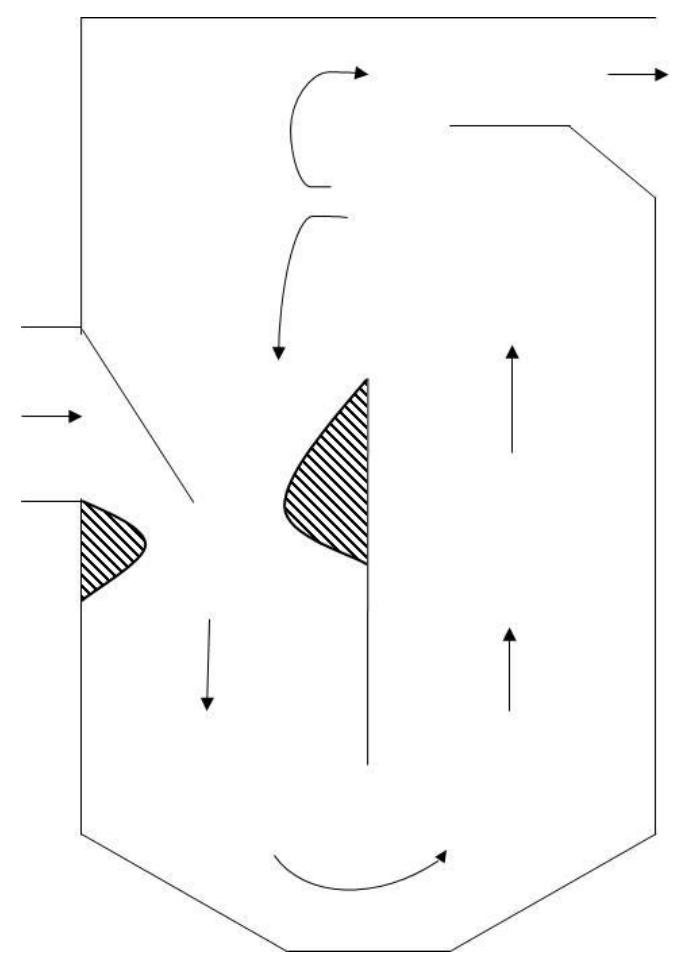

Figure 8. Suction unit scheme proposed by Koske (M. Kanno 1984) 
Koske was unclear about how the velocity inside the structure was controlled, given that there were no pumps. In addition, the method for removing full adsorbent particles from the system was unclear. A best guess is the structure was removed from the seawater and the particles were recovered then.

Forberg of Royal Institute of Technology proposed a wave powered floating plant concept with fluidized beds of pellets and mat adsorbent (Forberg, Lagstrom and Valla 1983). He presented six schemes utilizing different polyacrylamidoxime adsorbents in pellet and mat form, along with several floating platform structures. In one such structure (Figure 9), a 600 tonnes of uranium per year facility was composed of floating units. Each unit's dimensions were $426 \mathrm{~m}$ x $65 \mathrm{~m}$. The pellet structure adsorbent utilized 26 floating units and the mat structure adsorbent utilized 22 units. Forberg presented six cost estimates ranging from $\$ 160$ to $\$ 880 / \mathrm{kg} \mathrm{U}$ in 1983 dollars or $\$ 340$ to $\$ 1,900$ in 2010 dollars, where the mat scheme was cheapest and the pellet scheme was the most expensive. (M. Kanno 1984) The reason the mat scheme was cheaper because it modeled a multi-filament mat with greater exposed fiber exposure. That corresponded to a $60 \%$ increase in uranium uptake per year. The reuses are not listed. The adsorption capacity degradation is noted as negligible. 


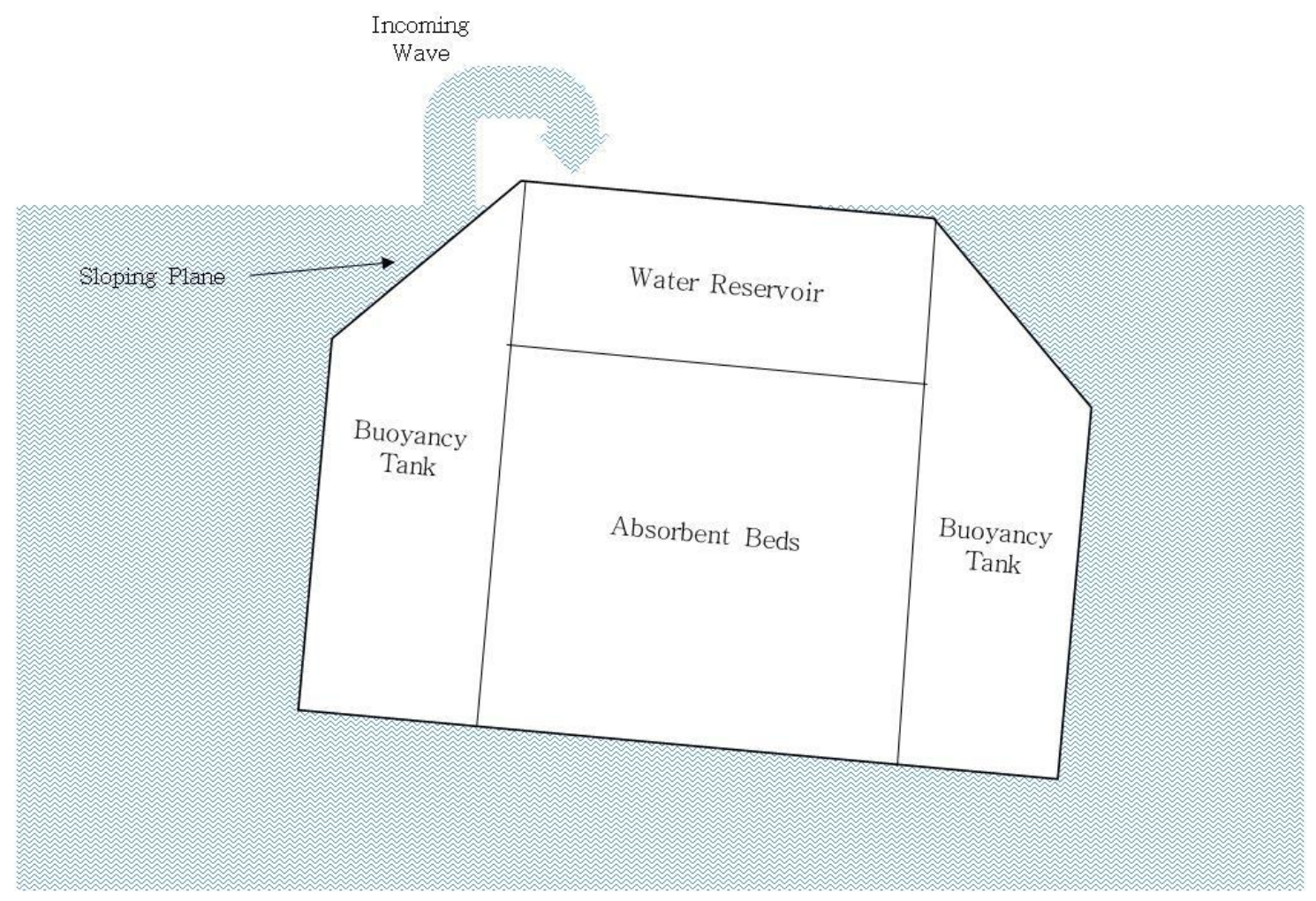

Figure 9. Forberg's Floating Platform (Forberg, Lagstrom and Valla 1983)

\section{0's}

In the 1990's, research continued to focus on amidoxime as the primary ligand for recovering uranium because of a significantly higher capacity (Sugo, et al. 2001) with the most intense activity shifting to Japan. The Japanese system used an amidoxime ligand attached to a high-density polyethylene (HDPE) substrate (Sugo, et al. 2001). This material pioneered by the Japanese constitutes the foundation for the current process described later in this paper.

The early estimates for amidoxime on an acrylic substrate came from (Nobukawa, Tamehiro, et al. 1989) and (Nobukawa, Michimoto, et al. 1990) presented in (Sekiguchi, et al. 1994). This work documented a shift from packed beds containing small adsorbent balls to fiber adsorbent in beds (strings of adsorbent.) Nobukawa proposed a mooring 
system where a series of beds packed with fibrous amidoxime adsorbents are suspended in the ocean current and uranium is collected during passage of seawater through the beds. The beds hung from boats presented in Figure 10. The adsorption capacity was assumed to be $3.2 \mathrm{~g} \mathrm{U} / \mathrm{kg}$ Ads. in 40 days. Nobukawa estimated the cost as 55,000 yen / $\mathrm{kg} \mathrm{U}$ in 1990 dollars or $\$ 900 / \mathrm{kg} \mathrm{U}$ in 2010 dollars (Sekiguchi, et al. 1994) . (These sources are in Japanese with English abstracts that include the capacity and the production cost.)

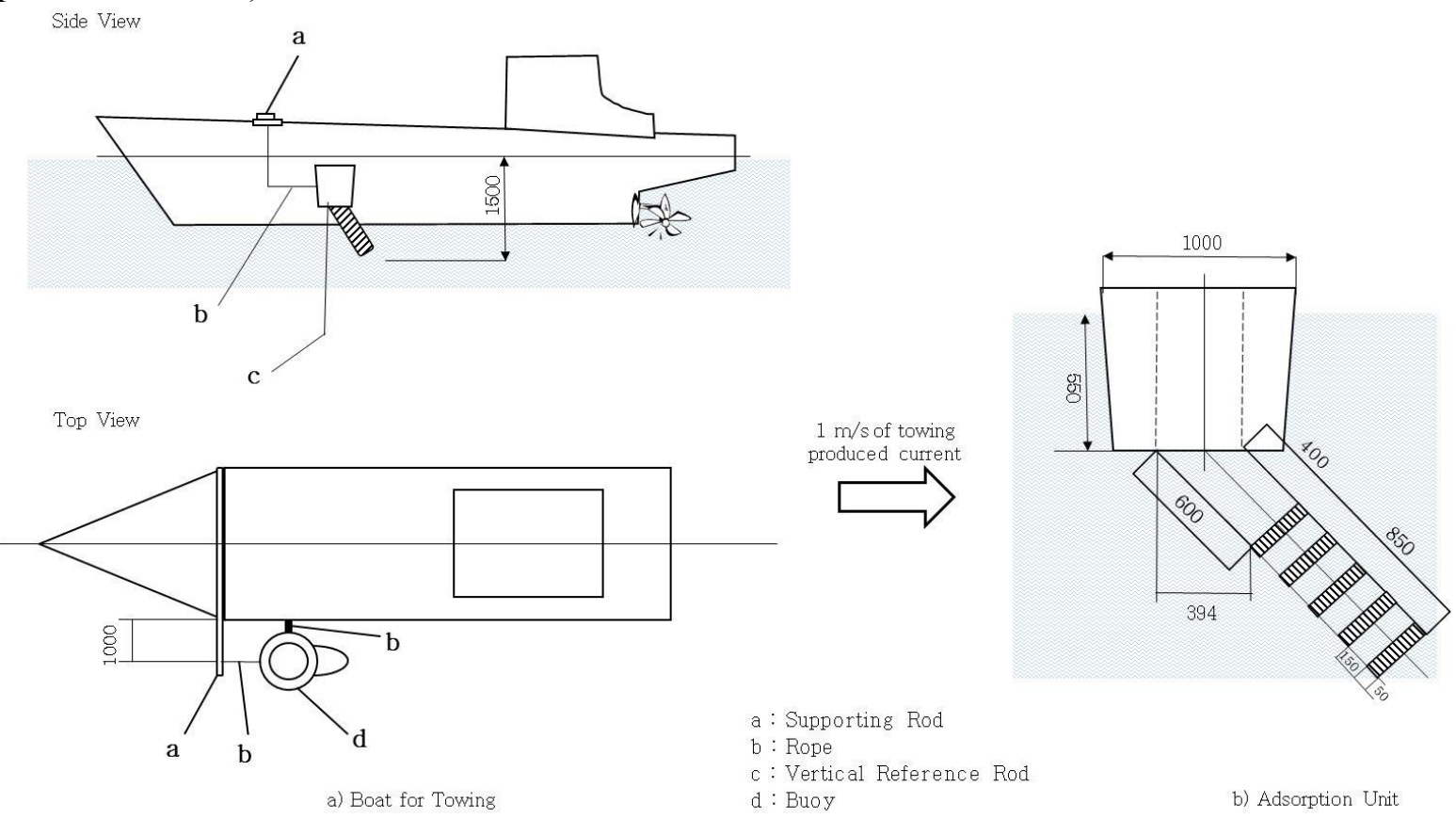

Figure 10. Nobukawa's Mooring Scheme (Sekiguchi 1994)

(Nobukawa, Kitamura, et al. 1994) went on to report results of field with updated adsorbent performance and present a second set of cost estimates. He employed the same amidoxime ligand on an acrylic fiber adsorbent that was used in his earlier work (Nobukawa, Tamehiro, et al. 1989) The field experiments explored the effect of seawater velocity on adsorption by moving adsorbent through seawater (hanging braids from a 
boat) versus allowing adsorbent to sit at sea (hanging from a bouy.) The results showed increased adsorption with higher velocities. Nobukawa noted the adsorbent floated inside the cages which allowed for increased permeability. This fiber based adsorbent (Nobukawa 1989) was packed into metal cages and hung from boats as shown in Figure 11.

The cost estimate of $\$ 495 / \mathrm{kg} \mathrm{U}$ (2010 dollars) assumed $4.6 \mathrm{~g} \mathrm{U} / \mathrm{kg}$ adsorbent at 60 days of mooring with boats towing adsorbent. This cost is low relative to other cost estimates, but the very optimistic adsorption capacity was never before observed experimentally: Nobukawa linearly extrapolated the 60 day capacity based on a few days of data. The paper does not mention the number of reuses or loss per use assumed for the cost analysis.

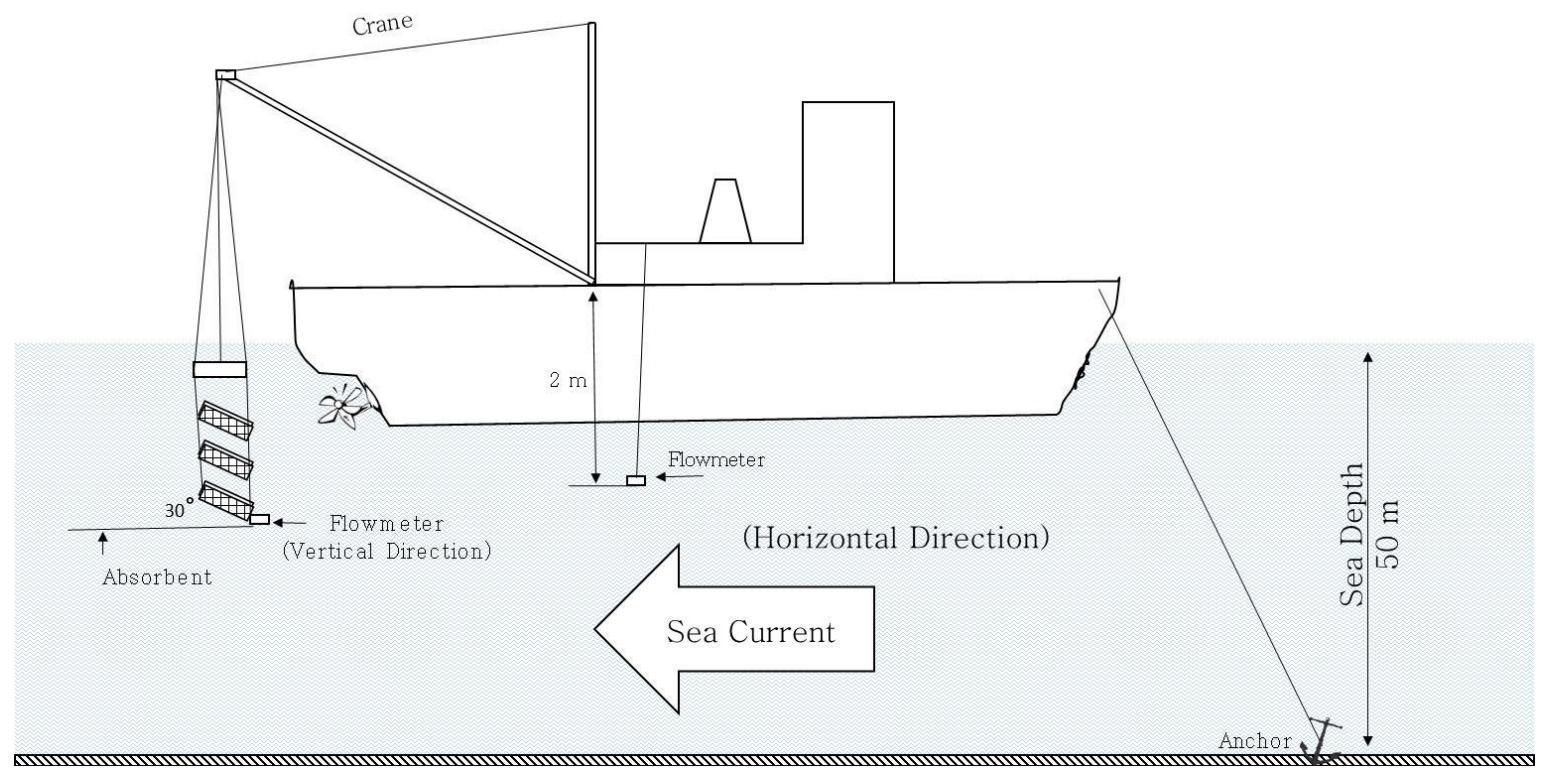

Figure 11. Nobukawa scheme for hanging adsorbent beds off boats (Nobukawa, Kitamura, et al. 1994) 
Around the same time of Nobukawa's estimates from the late 1980s to the early 1990s, (Uezu et al., 1988; Saito et al., 1990) was researching amidoxime ligands attached to high density polyethylene adsorbent (Sekiguchi, et al. 1994). Although the results were published without any cost estimates, it appeared to be the first instance of radiationinduced graft polymerization in creation of a ligand for uranium recovery from seawater. The process also used acrylonitrile onto a porous polyethylene hollow fiber to produce amidoxime from the cyano group. Uezu reported the capacity as $0.27 \mathrm{~g} / \mathrm{kg} \mathrm{U}$ in 25 days. The difference between this adsorbent and the amidoxime-HDPE adsorbents discussed next was the structure of the HDPE: Uezu used a hollow fiber versus a solid fiber.

\section{TO TODAY}

The first cost estimate for the amidoxime-HDPE adsorbent came from (Sugo, et al. 2001). (Sugo 2001) employed the amidoxime ligand grafting process previously discussed, Uezu's, one that utilized electron beam irradiation to open grafting sites on the HDPE. Sugo was also the first investigator to report an experimentally observed durability for the amidoxime adsorbent. Based upon five elution-adsorption cycles, Sugo found that the adsorbent lost $5 \%$ of its capacity per reuse. Sugo observed that increasing the surface area of the fibers and mooring in higher temperature seawater both led to increased adsorption. He set mooring campaign length to 60 days and assumed 20 uses of adsorbent before it is disposed.

Although experimental results at the time only supported a 60 day uranium uptake of $2 \mathrm{~g} \mathrm{U} / \mathrm{kg}$ adsorbent, the cost analysis hypothesized a capacity of $6 \mathrm{~g} / \mathrm{kg}$ ads. It assumed that the adsorbent fibers were packed into metal cages and suspended about $10 \mathrm{~m}$ beneath the ocean surface using weights and floats. Each adsorbent bed weighed slightly 
over 1 tonne containing $125 \mathrm{~kg}$ of adsorbent, around 320,000 beds in the ocean a year to recover 1,200 tonnes of $U$. The beds are shown in Figure 12.

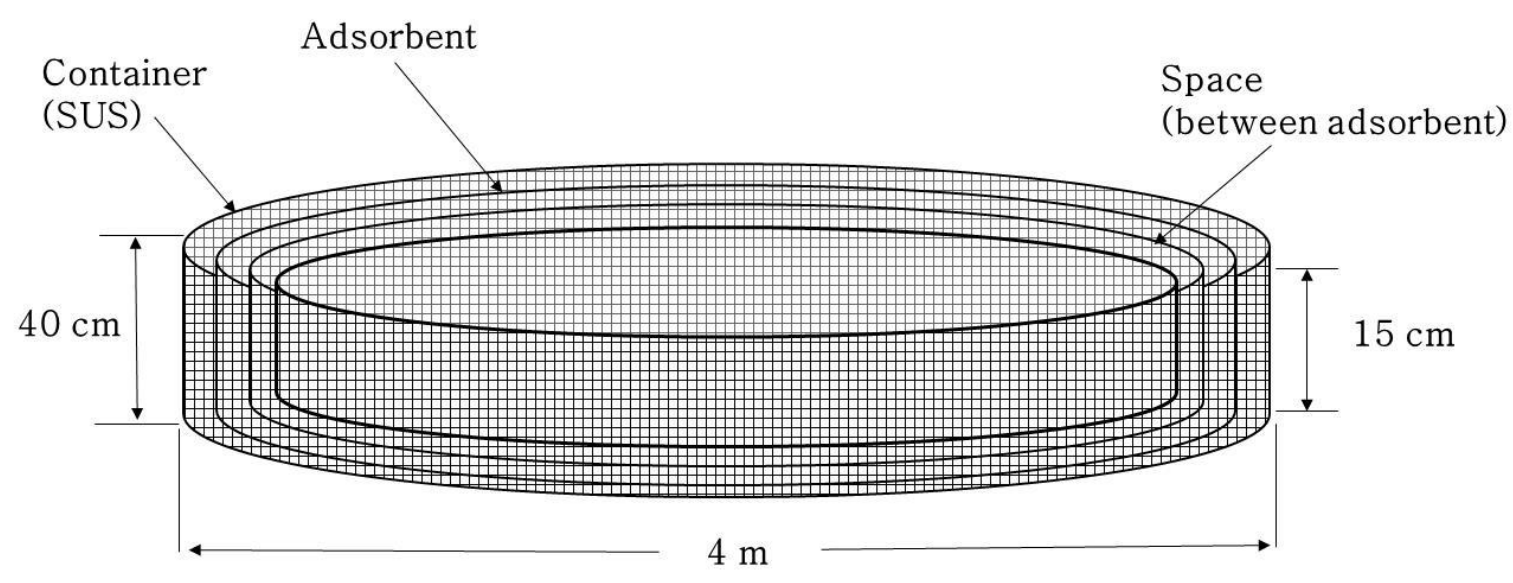

Figure 12. Adsorption bed loaded with adsorbent (Sugo, et al. 2001)

Three mooring systems were proposed for the adsorbent beds: a buoy method (shown in Figure 13), a floating body method, and a chain-binding method. The buoy method hung 100 adsorption beds from a buoy. Given the duration of the recovery and elution operations, Sugo recognized that in order to produce the target of 1,200 tonnes $U$ per year, the inventory of adsorbent had to be $40 \%$ larger than the amount in seawater at any given time. The second proposed method was a system of floating bodies that acted as a large buoy or platform. Each body had 54,000 adsorbent beds and a crane atop the body winched up the beds. Recovery ships were used to move adsorbent to and from shore. The final strategy was a chain based 'ski lift' strategy. Adsorbent beds are attached to chains and move continuously from shore to sea and back. Buoys keep the adsorbent at a fixed height in seawater. The total chain loop length to produce 1,200 tonnes U/year was found to be $320 \mathrm{~km}$ or 200 miles. The costs for each mooring strategy are presented below. Table 1 highlights the costs. 


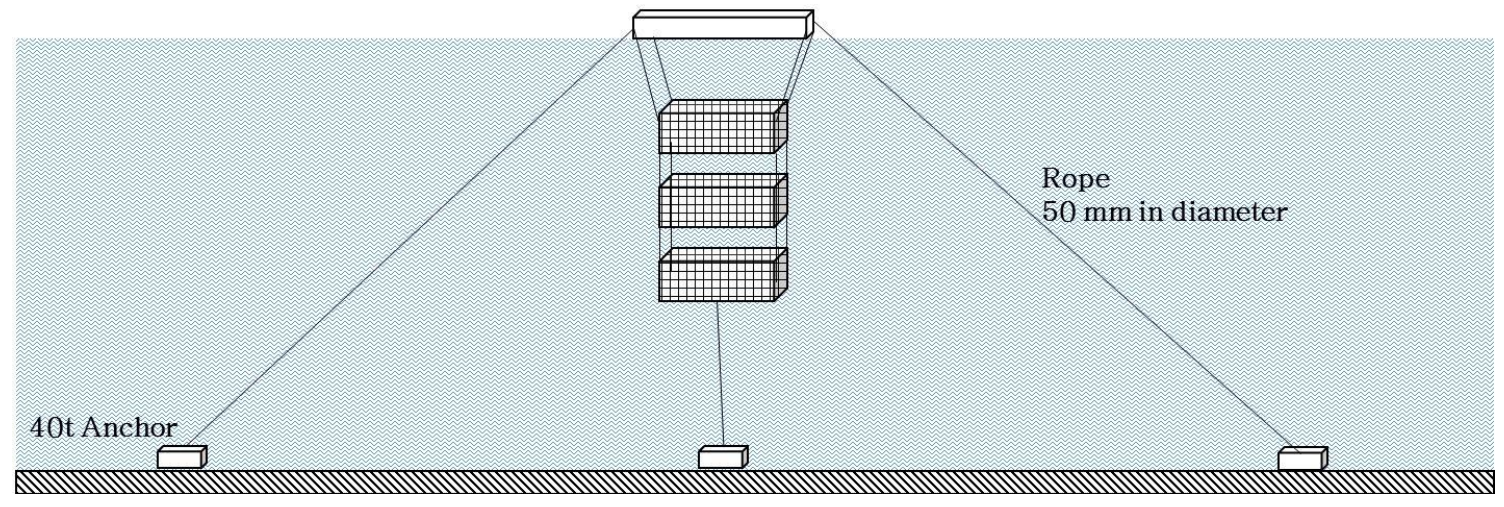

Figure 13. Sugo's Buoy Mooring Strategy (Sugo, et al. 2001)

Table 1. Mooring Strategy Cost (Sugo, et al. 2001)

\begin{tabular}{|l|l|}
\hline Mooring Strategy & Cost $(2010 \$ / \mathrm{kg} \mathrm{U})$ \\
\hline Buoy method & $\$ 676$ \\
\hline Floating body method & $\$ 632$ \\
\hline Chain-binding method & $\$ 362$ \\
\hline
\end{tabular}

Although Sugo presented novel mooring strategies, his cost analysis parameters -20 uses of adsorbent with $6 \mathrm{~g} \mathrm{U} / \mathrm{kg}$ adsorbent - were not borne out by the measured performance data.

The Japanese Atomic Energy Agency Japan (JAEA) and the Atomic Energy Research Institute (JAERI) built upon Sugo's work by introducing free standing braided adsorbent systems versus large structure based mooring strategies (M. Tamada, et al. 2006). Tamada noted that the mooring costs associated with the large structures were dominating the overall system costs and introduced the braids as a means of reducing the mass of material the ships needed to convey. Using the radiation grafted polyethylene amidoxime fibers, the adsorbent performance was taken to be $2 \mathrm{~g} \mathrm{U} / \mathrm{kg}$ adsorbent in 60 days and the adsorbent was used six times with 5\% loss per use. The mooring strategy was to tie $60 \mathrm{~m}$ long adsorbent braids to chain that had been anchored to the seabed and 
allow the braids to float to the surface, like a kelp field. Work boats would winch up the chain in order to moor and recover the adsorbent braids, and the braids would be taken back to shore for elution and preparation for redeployment. Figure 14 shows the mooring operation. Tamada estimated this cost as $\$ 1,000 / \mathrm{kg} \mathrm{U}$.

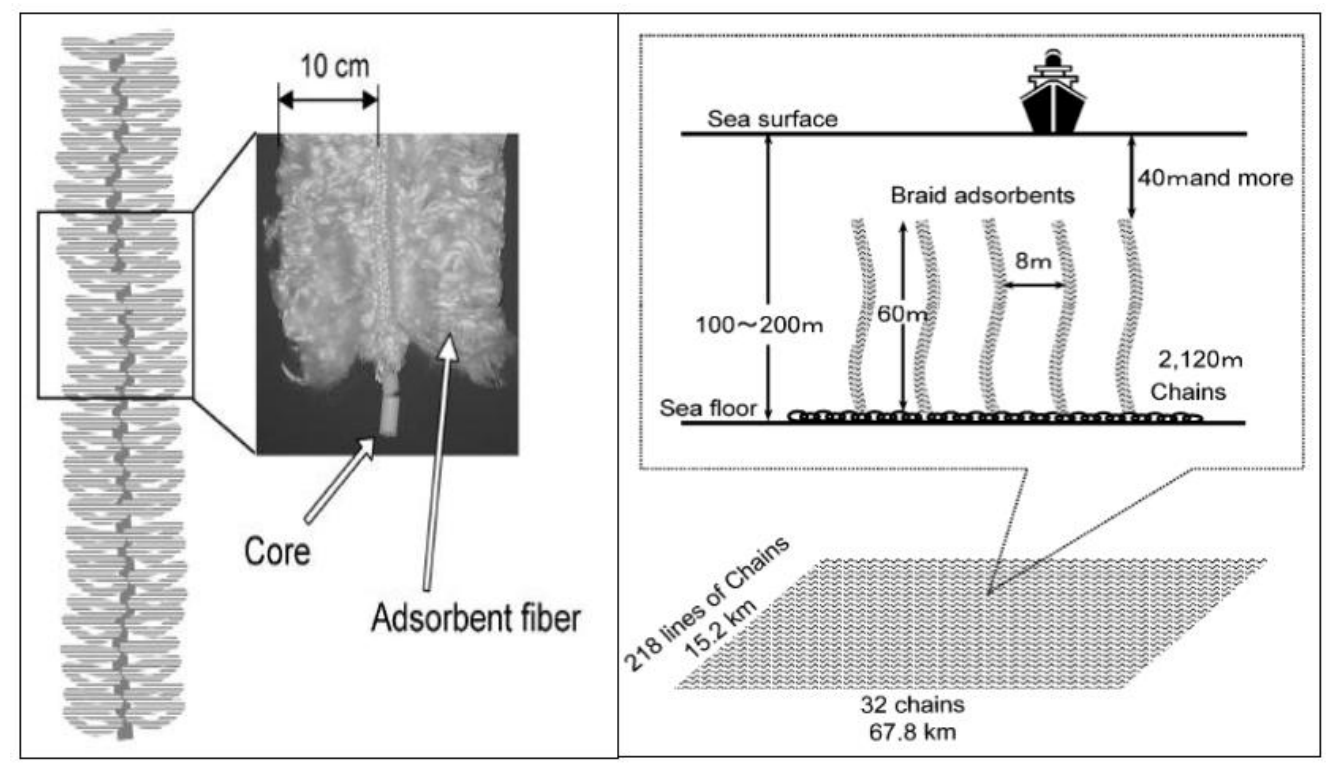

Figure 14. Braid Adsorbent and Mooring System (Tamada et al., 2006)

Oak Ridge National Laboratory in conjunction with The University of Texas at Austin evaluated and updated this cost estimate and model (Sachde 2011) (Schneider and Sachde 2013). The evaluation developed an independent cost estimate for the chemical process and adsorbent performance as in (Tamada 2006). Some modifications to the process published by JAEA were made; for instance, ORNL researchers had found that a hydrophilic group, not present in (Tamada 2006) but noted in other Japanese publications, was necessary in order to attain capacities approaching those claimed by JAEA. The US cost estimate also added financial modeling reflecting a private venture in the US, accounted for adsorbent degradation, and included adsorbent and chemical 
disposal costs. The estimated uranium production cost for the JAEA system was $\$ 1,220$ / $\mathrm{kg}$ U. Accounting for a 5 percent per-recycle adsorbent capacity degradation rate had greatest impact on cost of the changes mentioned above. The assumption was based upon experimental results in (Sugo, et al. 2001)

Schneider and Sachde (2011) also estimated uncertainties in a detail not seen in previous or past estimates. They considered three types of uncertainties: decision variables such as 1,200 tonnes U per year, value parameters such as discount rate, and empirical quantities such as equipment cost. They combined uncertainties in a Monte Carlo analysis. The 2-sigma (95\%) confidence interval on the uranium production cost was $\$ 689 / \mathrm{kg}$ U to $\$ 2850 / \mathrm{kg}$ U. The reason for the large uncertainty was led by the adsorbent capacity expected value of $2 \mathrm{~g} \mathrm{U} / \mathrm{kg}$ Ads. and it's standard deviation of $0.5 \mathrm{~g} /$ $\mathrm{kg}$. If the adsorption capacity performance was better-quantified, so that it could be said with certainty that the capacity is $2 \mathrm{~kg} \mathrm{U} / \mathrm{t}$ ads, then the $95 \%$ confidence interval would refine to $\$ 1030 / \mathrm{kg} \mathrm{U}$ to $\$ 1430 / \mathrm{kg} \mathrm{U}$. If degradation rate of adsorbent reuse of $5 \%$ was known with no uncertainty versus $2.5 \%$ standard deviation, the interval would shrink to $\$ 1110 / \mathrm{kg} \mathrm{U}$ to $\$ 1350 / \mathrm{kg} \mathrm{U}$, holding all else constant and the previous change of certainty of capacity. This analysis showed the importance of fully quantifying the performance of the technology and reiterated the technology is still in the early stages of development.

In 2011, a US group led by ORNL began to develop a series of adsorbents that built upon the Japanese amidoxime-HDPE textile. The University of Texas at Austin (UT) group collaborated with ORNL to provide cost estimates for these adsorbents. In 2012, (Schneider and Lindner 2012) built upon seawater experiments and kinetics modeling (Tsouris, et al. 2012) that demonstrated a 60-day uranium uptake of $2.76 \mathrm{~g} \mathrm{U} /$ $\mathrm{kg}$ ads. The cost estimate incorporated changes to the adsorbent grafting chemistry to more accurately describe the ligand production chemistry. The update also included a 
new mooring strategy: the adsorbent elution and regeneration processes were moved offshore, taking place a large boat called a 'mothership.' This modification reduced the size and cost of the work boats being used to service the adsorbent field. A supply ship carried product, spent chemicals, and spent adsorbent from the mothership to shore and replenished the mothership with fresh chemicals and replacement adsorbent.

(Schneider and Lindner 2012) explored disposal options for adsorbent: selling the adsorbent as scrap, reusing the adsorbent material (high density polyethylene (HDPE) substrate), or reusing the adsorbent fiber (the spun HDPE as opposed to the raw material.) They also accounted for economies of scale in the production of chemicals whose markets would be significantly impacted by implementation of the uranium recovery from seawater system. Finally, they included cost reductions from sale of a potential coproduct, vanadium. It was later noted that vanadium is an unlikely co-product since it is very difficult to elute from the amidoxime adsorbent without damaging the ligand. They mentioned lanthanides and precious metals as likely other co-products, but noted additional experiments at larger scales would need to confirm yields. They published the cost estimate at $\$ 1,000 / \mathrm{kg} U$ and considered sensitivity cases as summarized below in Table 2 . 
Table 2. Summary of Options and Updates (Schneider and Lindner 2012)

\begin{tabular}{|l|l|c|}
\hline \multicolumn{1}{|c|}{ Category } & \multicolumn{1}{|c|}{ Item } & $\begin{array}{c}\text { Percent } \\
\text { Change }\end{array}$ \\
\hline $\begin{array}{l}\text { ORNL Adsorbent \& } \\
\text { Performance }\end{array}$ & $\begin{array}{l}\text { Assumes reference conditions except } \\
\text { adsorption capacity of 2.76 ('Flow } \\
\text { Combined') and the ORNL process for } \\
\text { adsorption production. }\end{array}$ & $\begin{array}{c}--(-19 \% \\
\text { change from } \\
\text { the reference } \\
\text { case) }\end{array}$ \\
\hline $\begin{array}{l}\text { Offshore Elution } \\
\text { and Purification }\end{array}$ & & $-7 \%$ \\
\hline $\begin{array}{l}\text { Adsorption } \\
\text { Capacity Scenarios }\end{array}$ & 2.76 g U / kg ads. & - \\
\hline $\begin{array}{l}\text { End Use Options } \\
\text { Scenarios }\end{array}$ & Sell as scrap & $-15 \%$ \\
\hline $\begin{array}{l}\text { Reuse Chemicals } \\
\text { Scenarios }\end{array}$ & $\begin{array}{l}\text { Reuse hydroxylamine, } \\
\text { dimethylsulfoxide, and methanol }\end{array}$ & $-28 \%$ \\
\hline Economies of Scale & - & $-6 \%$ \\
\hline $\begin{array}{l}\text { Incineration Cost } \\
\text { Cor Hazardous }\end{array}$ & - & $-25 \%$ \\
\hline Co-products & - & $-11 \%$ \\
\hline
\end{tabular}

* Rounding to two significant figures accounts for the difference.

An update to this analysis was published in (Schneider and Lindner 2014). This updated the capacity to $3.09 \mathrm{~g} \mathrm{U} / \mathrm{kg}$ ads. based on measurements at PNNL of new, high surface area fibers prepared at ORNL (Kim, et al. 2013 and Kim, et al. 2014). The reduced radius and noncylindrical cross section of the new fiber increases its surface area to mass ratio which improves the amount of ligand contacted with the water per unit mass of adsorbent. The update also revised chemical usage for ligand grafting and high density polyethylene fiber production. The heavy, stainless steel chain in previous 
estimates, (M. Tamada, et al. 2006), which was costly to purchase and maintain, was replaced by a high strength, advanced lightweight co-polymer material rope. The overall system cost from (Schneider and Lindner 2012) was $\$ 640 / \mathrm{kg} \mathrm{U}$.

Another recent cost estimate for uranium recovery from seawater came from Massachusetts Institute of Technology (MIT.) They published a report exploring two new mooring strategies, a 3D adsorbent net and symbiotic system of adsorbent attached to wind turbines. (Baelden 2013) Their analysis assumed the same amidoxime adsorbent analyzed in (Schneider and Sachde 2013): $2 \mathrm{~g} / \mathrm{kg}$, HDPE (high density polyethylene) substrate. The MIT team assumed that the number of uses could be increased to 18 from 6 and the adsorption capacity loss per reuse was reduced to $4.4 \%$ from $5 \%$. The motivation for their work was the high cost for mooring in (Schneider and Sachde, The Cost of Recovering Uranium from Seawater by a Braided Polymer Adsorbent System 2013) and the relatively low number of reuses of the adsorbent.

The net system utilizes one large ship to perform the recovery, elution and mooring functions. As shown in Figure 15 and Figure 16, the ship is designed to winch up the adsorbent, elute uranium, regenerate the adsorbent, and lower it back into place in a single continuous campaign. The savings are largely a result of reducing the number of ships and including the elution on board the ship. Also, by assuming that the adsorbent braid trunks will bear the tensile load in the 3D net, MIT eliminates most of the chain present in the JAEA and ORNL designs. MIT also claimed that a scaled-down onboard elution capacity, attained by increasing the frequency of trips to shore, led to a further cost reduction. MIT placed the cost of the 3-D net scenario at $\$ 325 / \mathrm{kg} \mathrm{U}$. 


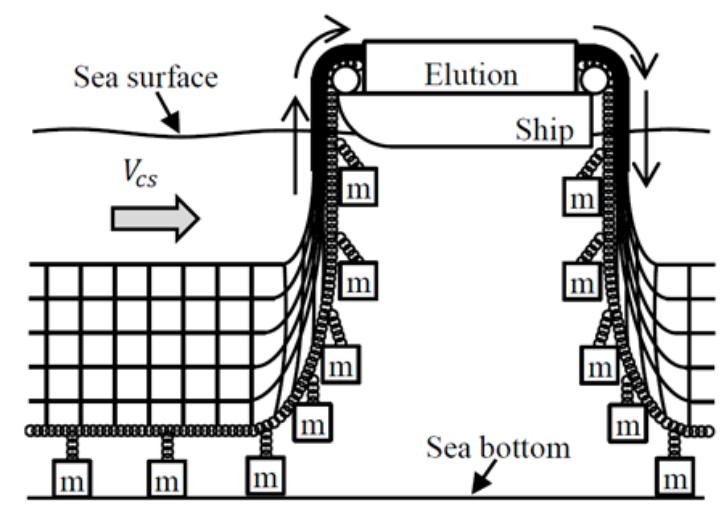

Figure 15. Side View of 3D Net Mooring and Recovery System (Baelden 2013)

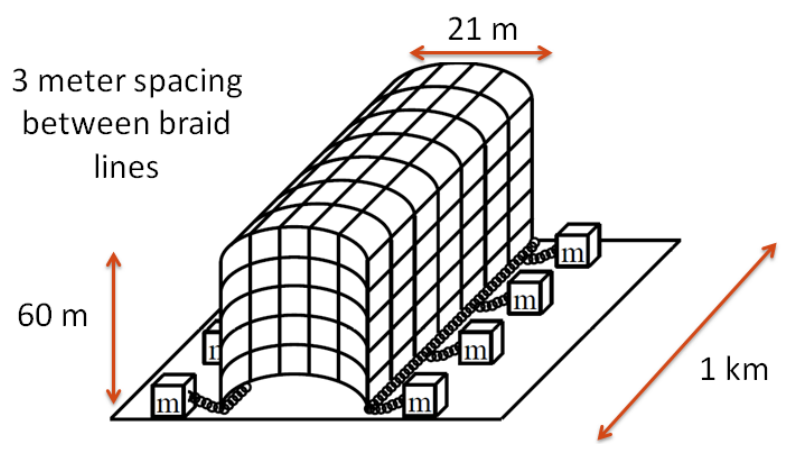

Figure 16. Section of the 3D Net (Number of braided lines is reduced and braided lines inside the net are not shown for clarity) (Baelden 2013)

(Arrows and lengths are added for clarity.)

The 3D net posed some technical feasibility concerns. The rate at which the ship winches the adsorbent to the surface allowed insufficient time for the continuous elutionregeneration system to be realistic. The adsorbent net is processed at a rate of 10 meters/minute, implying that adsorbent elution and regeneration is completed in under one minute given the size of the chemical reactors. An additional potential issue is the mooring and replacement of spent adsorbent net. Each $3 \mathrm{~km}$ long x $21 \mathrm{~m}$ wide net is a single closely coupled structure. The cost analysis does not allow for repair of damaged 
or fouled adsorbent net or replacement of adsorbent that has reached the end of its lifetime.

The MIT team also produced a cost estimate for a symbiotic system of braids and elution stations attached to offshore wind turbines. The system used the same adsorbent braids described in (M. Tamada, et al. 2006) and (Schneider and Sachde 2013). The wind turbines power the winching system that conveys the adsorbent through seawater as well as the co-located elution reactor. The system was sized to produce $\sim 1$ tonne $\mathrm{U} / \mathrm{yr}$ per wind turbine. As such, it would require 20 100-m long adsorbent 'loops' with a total belt length of $4,000 \mathrm{~m}$ so that each turbine would carry 60 tonnes of adsorbent. An illustration of this system is shown in Figure 17.

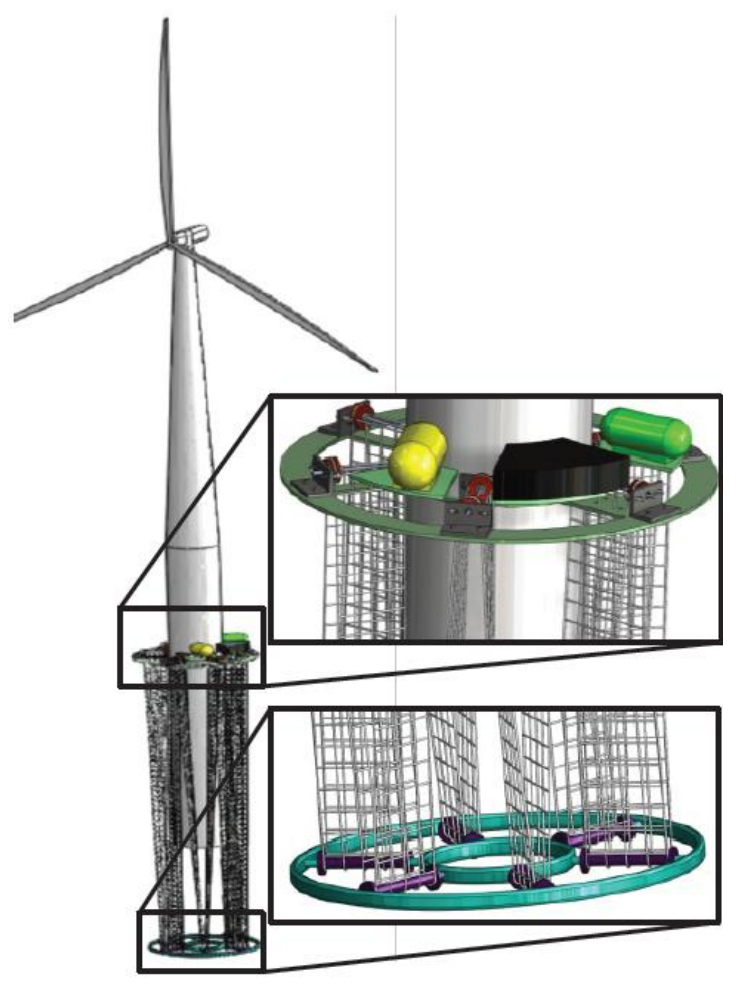

Figure 17. Symbiotic Mooring Scheme. For easiness to see, only 6 loops of belt instead of 20 are drawn in the figure. (Baelden 2013) 
The cost of uranium recovery for the symbiotic wind turbine system was estimated to be $\$ 400 / \mathrm{kg} \mathrm{U}$. Certain challenges are faced by this design. Drag forces on adsorbent might be considerable given the large braid lengths needed to attain the desired production rate and the fact that the braids are not free-floating as in (M. Tamada, et al. 2006) and (Schneider and Sachde 2013). Also, the continuously-operating elution and regeneration system may face the same timing and plausibility issues as arose with the 3D net scheme.

\section{CONCLUSIONS}

The literature review explored cost estimates for uranium recovery from seawater from the 1960s to today. Some studies throughout this period (e.g. (Davies 1964) (Bitte, Keller and Ludwig 1983) (Forberg, Lagstrom and Valla 1983)), produced notably low cost estimates. Generally, these works do not fully document the economic modeling assumptions or methods, and/or major components of the cost (adsorbent, mooring, and elution) are omitted, and/or the adsorption capacity and durability values used in the cost analysis were target values or otherwise not demonstrated by experiment. Nonetheless, all studies were left in this review in order to provide a continuous narrative from the 1960s to today.

The work in the 1960s and 1970s focused on hydrous titanium oxide and packed bed adsorbents. Much of the work published in the 1970s addressed the engineering challenge of bringing large volumes of water in contact with adsorbent, so proposals often involved the pumping of water through large structures. The 1980's marked the first publications focusing on the amidoxime adsorbent, initially in packed beds. Since it offers a substantially larger adsorption capacity, the amidoxime ligand ended the use of hydrous titanium oxide. Much of the work in the 1980's work still used pumping of water 
through beds as the method for exposing adsorbent to seawater. Work in the 1990's improved on the amidoxime grafting process through the use of electron or gamma radiation to open grafting sites on the polymer substrate and saw the development of a free form fiber adsorbent. The fibrous adsorbent could be deployed in a free-standing way if attached to a buoyant trunk, with no need for containers or packed beds. This change drove strategies where ocean water did not need to be actively pumped or moved; the costs and energy use associated with pumping had been seen to effectively cripple the economic viability of the technology. Adsorbent could now float in water and passively collect uranium. The 2000's to today have seen continued improvements in amidoxime ligand production chemistry as well as the fibrous polymer substrate. Notably, increasing the surface area of the fibers was shown to improve adsorption capacity, as more ligands are exposed to the water per mass of fiber. The most recent studies built upon the free form fiber adsorbent to create additional mooring schemes that used even less energy and resources. Finally, the methodological rigor and level of detail of the cost estimates has increased over time, as has the amount and realism of the experimental data used to support the cost estimates. Figure 18 shows a summary of the cost estimates and Table 3 provides details of the estimates reviewed in this paper. 
Table 3. Cost estimates for uranium recovery from seawater

\begin{tabular}{|c|c|c|c|c|c|c|c|c|c|c|c|}
\hline Source & Year & $\begin{array}{l}\text { Cost } \\
\text { Estimate } \\
(2010 \$)\end{array}$ & $\begin{array}{l}\text { Capacity } \\
\text { (g U / kg } \\
\text { ads.) }\end{array}$ & Adsorbent & Substrate & $\begin{array}{l}\text { Substrate } \\
\text { structure }\end{array}$ & $\begin{array}{l}\text { Mooring } \\
\text { Strategy }\end{array}$ & $\begin{array}{l}\text { Uses of } \\
\text { adsorbent }\end{array}$ & $\begin{array}{l}\text { Degradation } \\
\text { (\%/use) }\end{array}$ & Co-products & $\begin{array}{l}\text { Length of } \\
\text { Campaign } \\
\text { (Days) }\end{array}$ \\
\hline Davies & 1964 & $\$ 410$ & 0.26 & $\begin{array}{l}\text { Hydrous } \\
\text { Titanium } \\
\text { Oxide }\end{array}$ & $\begin{array}{l}\text { Solid } \\
\text { insoluble } \\
\text { resin beads - } \\
\text { glass wool }\end{array}$ & $\begin{array}{l}\text { Packed } \\
\text { beds with } \\
\text { support }\end{array}$ & $\begin{array}{l}\text { Tidal usage } \\
\text { of lagoons }\end{array}$ & $\begin{array}{l}\text { Not } \\
\text { Listed }\end{array}$ & Not Listed & None listed & 20 \\
\hline Davies & 1964 & $\$ 210$ & 0.26 & $\begin{array}{l}\text { Hydrous } \\
\text { Titanium } \\
\text { Oxide } \\
\end{array}$ & $\begin{array}{l}\text { Solid } \\
\text { insoluble } \\
\text { resin beads - } \\
\text { muslin }\end{array}$ & $\begin{array}{l}\text { Packed } \\
\text { beds }\end{array}$ & $\begin{array}{l}\text { Tidal usage } \\
\text { of lagoons }\end{array}$ & $\begin{array}{l}\text { Not } \\
\text { Listed }\end{array}$ & Not Listed & None listed & 7 \\
\hline Kanno & 1981 & $\$ 3,400$ & 0.196 & $\begin{array}{l}\text { Hydrous } \\
\text { Titanium } \\
\text { Oxide } \\
\end{array}$ & $\begin{array}{l}\text { Precipitate } \\
\text { and is } \\
\text { prepared by } \\
\text { sifting onto a } \\
\text { mesh }\end{array}$ & $\begin{array}{l}\text { Packed } \\
\text { beds }\end{array}$ & $\begin{array}{l}\text { Pumping and } \\
\text { fixed bed of } \\
\text { adsorbent, } \\
\text { on-shore } \\
\text { parallel }\end{array}$ & 20 & $0.10 \%$ & None listed & 10 \\
\hline Kanno & 1981 & $\$ 2,300$ & 0.200 & $\begin{array}{l}\text { Hydrous } \\
\text { Titanium } \\
\text { Oxide }\end{array}$ & $\begin{array}{l}\text { Precipitate } \\
\text { and is } \\
\text { prepared by } \\
\text { sifting onto a } \\
\text { mesh }\end{array}$ & $\begin{array}{l}\text { Packed } \\
\text { beds }\end{array}$ & $\begin{array}{l}\text { Pumping and } \\
\text { fixed bed of } \\
\text { adsorbent } \\
\text { aligned } \\
\text { breakwater }\end{array}$ & 20 & $0.10 \%$ & None listed & 10 \\
\hline Kanno & 1981 & $\$ 1,700$ & 0.200 & $\begin{array}{l}\text { Hydrous } \\
\text { Titanium } \\
\text { Oxide }\end{array}$ & $\begin{array}{l}\text { Precipitate } \\
\text { and is } \\
\text { prepared by } \\
\text { sifting onto a } \\
\text { mesh }\end{array}$ & $\begin{array}{l}\text { Packed } \\
\text { beds }\end{array}$ & pumps & 20 & $0.10 \%$ & None listed & 10 \\
\hline Kanno & 1981 & $\$ 2,600$ & 0.2 & $\begin{array}{l}\text { Hydrous } \\
\text { Titanium } \\
\text { Oxide }\end{array}$ & $\begin{array}{l}\text { Precipitate } \\
\text { and is } \\
\text { prepared by } \\
\text { sifting onto a } \\
\text { mesh }\end{array}$ & $\begin{array}{l}\text { Packed } \\
\text { beds }\end{array}$ & $\begin{array}{l}\text { cubes in } \\
\text { water with } \\
\text { offshore }\end{array}$ & 20 & $0.10 \%$ & None listed & 10 \\
\hline Driscoll & 1983 & $\$ 800$ & 0.094 & Amidoxime & Acrylic Fiber & $\begin{array}{l}\text { Small } \\
\text { Radius } \\
\text { Fibers }\end{array}$ & $\begin{array}{l}\text { pumps and } \\
\text { offshore } \\
\text { platform }\end{array}$ & $\begin{array}{l}\text { Not } \\
\text { Listed }\end{array}$ & Not Listed & None & 7 \\
\hline
\end{tabular}




\begin{tabular}{|c|c|c|c|c|c|c|c|c|c|c|c|}
\hline \multicolumn{12}{|c|}{ Table 3 (continued) } \\
\hline Driscoll & 1983 & $\$ 640$ & 0.094 & Amidoxime & Acrylic Fiber & $\begin{array}{l}\text { Small } \\
\text { Radius } \\
\text { Fibers }\end{array}$ & pumps & $\begin{array}{l}\text { Not } \\
\text { Listed }\end{array}$ & Not Listed & $\begin{array}{l}\text { Molybdenum } \\
\text { and } \\
\text { Vanadium }\end{array}$ & 7 \\
\hline Bitte & 1983 & $\$ 1,500$ & 7.2 & Amidoxime & Acrylic & $\begin{array}{l}\text { Fluidized } \\
\text { beds }\end{array}$ & $\begin{array}{l}\text { boats/floating } \\
\text { structures } \\
\text { with pumps }\end{array}$ & 10 & Not Listed & Not Listed & 360 \\
\hline Bitte & 1983 & $\$ 290$ & 6.5 & Amidoxime & Acrylic & $\begin{array}{l}\text { Fluidized } \\
\text { beds }\end{array}$ & $\begin{array}{l}\text { boats/floating } \\
\text { structures } \\
\text { with pumps }\end{array}$ & 25 & Not Listed & Not Listed & 360 \\
\hline Koske & 1983 & $\$ 2,100$ & $70 \%$ & Amidoxime & Acrylic & $\begin{array}{l}\text { Granulate } \\
\text { in } \\
\text { structure }\end{array}$ & $\begin{array}{l}\text { Floating } \\
\text { structure that } \\
\text { utilizes } \\
\text { convection - } \\
\text { Loop } \\
\text { formation }\end{array}$ & $\begin{array}{l}\text { Not } \\
\text { Listed }\end{array}$ & Not Listed & Not Listed & $\begin{array}{l}\text { Not } \\
\text { Listed }\end{array}$ \\
\hline Koske & 1983 & $\$ 980$ & $80 \%$ & Amidoxime & Acrylic & $\begin{array}{l}\text { Granulate } \\
\text { in } \\
\text { structure }\end{array}$ & $\begin{array}{l}\text { Floating } \\
\text { structure that } \\
\text { utilizes } \\
\text { convection - } \\
\text { Loop } \\
\text { formation, } \\
\text { Compares to } \\
\text { fluidized bed }\end{array}$ & $\begin{array}{l}\text { Not } \\
\text { Listed }\end{array}$ & Not Listed & Not Listed & $\begin{array}{l}\text { Not } \\
\text { Listed }\end{array}$ \\
\hline Forberg & 1983 & $\$ 2,000$ & 3.3 & Amidoxime & Acrylic & $\begin{array}{l}\text { Pellets in } \\
\text { Beds }\end{array}$ & $\begin{array}{l}\text { Wave } \\
\text { powered } \\
\text { floating } \\
\text { structure }\end{array}$ & $\begin{array}{l}\text { Not } \\
\text { Listed }\end{array}$ & $\begin{array}{l}0- \\
\text { "Negligible" }\end{array}$ & Not Listed & 27.5 \\
\hline Forberg & 1983 & $\$ 350$ & 5.28 & Amidoxime & Acrylic & $\begin{array}{l}\text { Mats, } \\
\text { free } \\
\text { floating }\end{array}$ & $\begin{array}{l}\text { Wave } \\
\text { powered } \\
\text { floating } \\
\text { structure } \\
\end{array}$ & $\begin{array}{l}\text { Not } \\
\text { Listed }\end{array}$ & $\begin{array}{l}0 \text { - } \\
\text { "Negligible" }\end{array}$ & Not Listed & 27.5 \\
\hline Nobukawa & $\begin{array}{l}1989 \& \\
1990\end{array}$ & $\$ 900$ & 3.2 & Amidoxime & Acrylic Fiber & $\begin{array}{l}\text { Fiber in } \\
\text { Beds }\end{array}$ & $\begin{array}{l}\text { Fiber in beds } \\
\text { hanging from } \\
\text { boats }\end{array}$ & $\begin{array}{l}\text { Not } \\
\text { Listed }\end{array}$ & Not Listed & Not Listed & 40 \\
\hline Nobukawa & 1994 & $\$ 500$ & 4.6 & Amidoxime & Acrylic Fiber & $\begin{array}{l}\text { Fiber in } \\
\text { Beds }\end{array}$ & $\begin{array}{l}\text { Fiber in beds } \\
\text { hanging from } \\
\text { boats }\end{array}$ & $\begin{array}{l}\text { Not } \\
\text { Listed }\end{array}$ & Not Listed & Not Listed & 60 \\
\hline
\end{tabular}


Table 3 (continued)

\begin{tabular}{|c|c|c|c|c|c|c|c|c|c|c|c|}
\hline Sugo & 2001 & $\$ 680$ & 6 & Amidoxime & $\begin{array}{l}\text { HDPE - } \\
\text { Radiation } \\
\text { Grafting }\end{array}$ & Fiber & Buoy method & 20 & $4 \%$ & Not Listed & 60 \\
\hline Sugo & 2001 & $\$ 640$ & 6 & Amidoxime & HDPE & Fiber & $\begin{array}{l}\text { Floating body } \\
\text { method (large } \\
\text { buoy) }\end{array}$ & 20 & $4 \%$ & Not Listed & 60 \\
\hline Sugo & 2001 & $\$ 370$ & 6 & Amidoxime & HDPE & Fiber & $\begin{array}{l}\text { Chain-binding } \\
\text { method in ski } \\
\text { lift strategy }\end{array}$ & 20 & $4 \%$ & Not Listed & 60 \\
\hline Tamada & 2007 & $\$ 1,000$ & 2 & Amidoxime & HDPE & Fiber & $\begin{array}{l}\text { Long free } \\
\text { floating braids } \\
\text { in kelp field } \\
\text { formation }\end{array}$ & 6 & Not Listed & Not included & 60 \\
\hline $\begin{array}{l}\text { Schneider } \\
\text { and Sachde }\end{array}$ & 2011 & $\$ 1,200$ & 2 & Amidoxime & HDPE & Fiber & $\begin{array}{l}\text { Long free } \\
\text { floating braids } \\
\text { in kelp field } \\
\text { formation }\end{array}$ & 6 & $5 \%$ & Not included & 60 \\
\hline $\begin{array}{l}\text { Schneider } \\
\text { and } \\
\text { Lindner }\end{array}$ & 2012 & $\$ 1,000$ & 2.76 & Amidoxime & HDPE & Fiber & $\begin{array}{l}\text { Long free } \\
\text { floating braids } \\
\text { in kelp field } \\
\text { formation }\end{array}$ & 6 & $5 \%$ & Not included & 60 \\
\hline $\begin{array}{l}\text { Schneider } \\
\text { and } \\
\text { Lindner }\end{array}$ & 2014 & $\$ 640$ & 3.08 & Amidoxime & HDPE & Fiber & $\begin{array}{l}\text { Long free } \\
\text { floating braids } \\
\text { in kelp field } \\
\text { formation - } \\
\text { uses small } \\
\text { boats to } \\
\text { recover }\end{array}$ & 6 & $5 \%$ & Not included & 60 \\
\hline $\begin{array}{l}\text { Baelden } \\
\text { (MIT) }\end{array}$ & 2013 & $\$ 330$ & 2 & Amidoxime & HDPE & Fiber & $\begin{array}{l}\text { Braids in 3-D } \\
\text { Net formation }\end{array}$ & 18 & $4.4 \%$ & Not included & 30 \\
\hline $\begin{array}{l}\text { Baelden } \\
\text { (MIT) }\end{array}$ & 2013 & $\$ 400$ & 2 & Amidoxime & HDPE & Fiber & $\begin{array}{l}\text { Symbiotic } \\
\text { System with } \\
\text { wind turbines }\end{array}$ & 18 & $4.4 \%$ & Not included & 38 \\
\hline
\end{tabular}




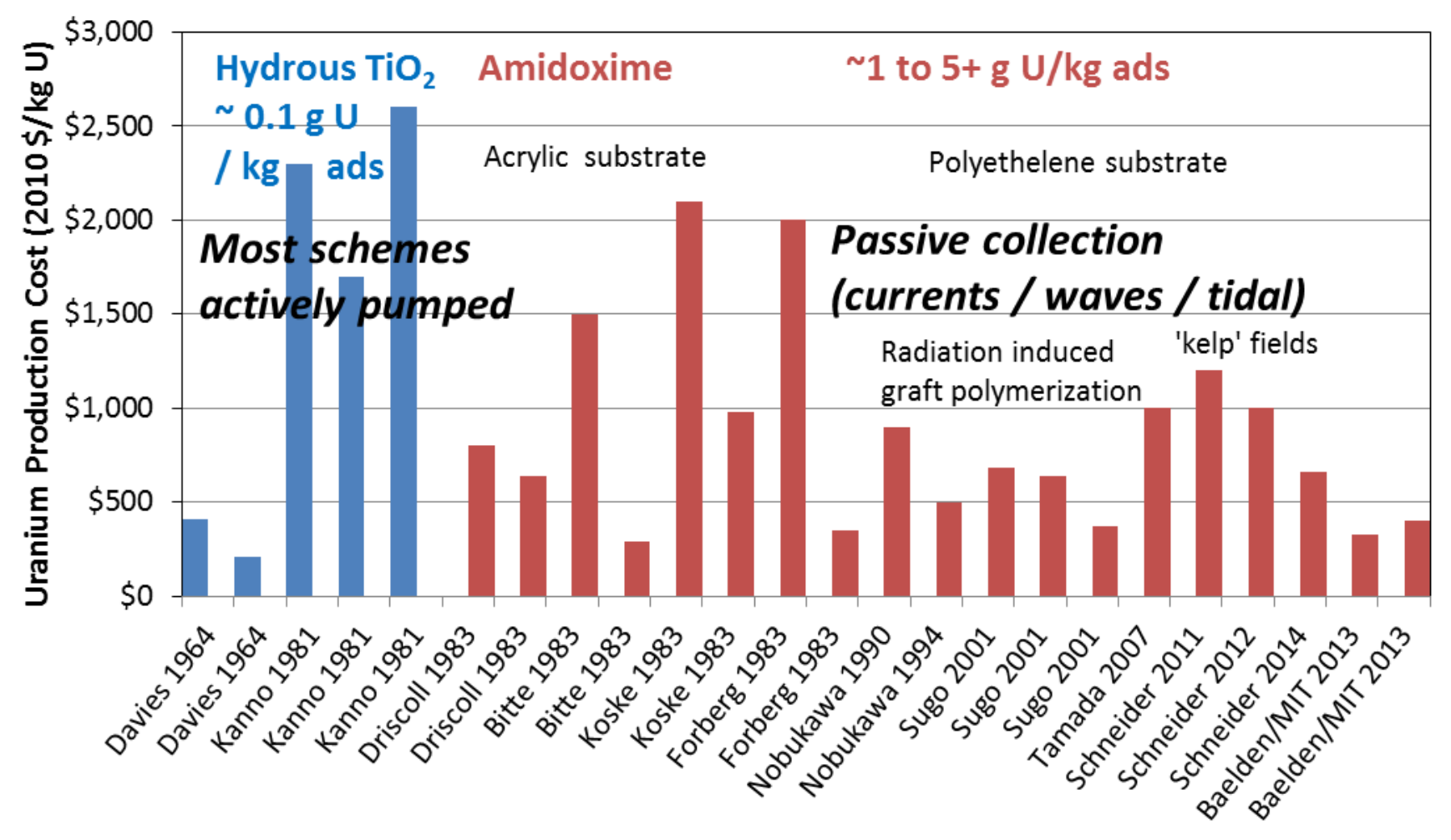

Figure 18. Summary of cost estimates.

The general conclusions of the body of research reviewed here are as follows:

-adsorption capacity was the largest driver of cost per unit mass of uranium when a new ligand or substrate proved to have a higher capacity, research using previous adsorbent was halted;

-durability measured as number of uses of the adsorbent and degradation of the adsorbent per use were also major cost drivers;

-a higher capacity did not necessarily mean a lower cost per unit mass of uranium. If the ligand or substrate was more expensive to produce, the overall cost may increase relative to a similar system with a lower adsorption capacity but cheaper materials; 
-many different substrates were employed, with high density polyethylene being the most widely and recently used;

-passive mooring systems were more economical than systems that involve pumping seawater;

- given the kinetics of uranium adsorption, longer adsorption campaigns yielded more uranium but there were diminishing returns to extending the adsorption campaign;

-small diameter fibrous adsorbents had higher capacities per unit mass of adsorbent than beads or precipitates that require packaging;

-co-products could potentially reduce the cost of recovering the primary uranium product.

For a recovery system to be economically viable, the ratio of adsorption capacity in $\mathrm{g} \mathrm{U} / \mathrm{kg}$ ads to the cost of producing the adsorbent material should be as large as possible. The mooring strategy needs to be passive and consume minimal energy. That means relying on the natural motion of the seawater rather than induced movement of the adsorbent or seawater to collect uranium.

In closing, none of the reviewed systems are economically competitive against current terrestrial mining. If there is a near-term role for uranium production from seawater, it is likely as 'backstopping' technology that reduces the uncertainty surrounding the security and adequacy of supply. Future research should focus not only on advancing the basic science of adsorbent materials, but also on demonstrating the technology at pilot scale. An engineering-scale demonstration in which adsorbent material is repeatedly reused would address key aspects of the technology where cost estimates still rest upon assumptions regarding chemical use and equipment requirements if the system is scaled up from today's bench-scale experiments. It would also replace assumptions and extrapolations tied to multiple reuses of the adsorbent with repeatable 
measured data. 


\section{References}

Baelden, C. et al. "Extraction of Uranium from Seawater: Design and Testing of a Symbiotic System." Massachusetts Institute of Technology, 2013.

Bitte, J., A. Keller, and K.P. Ludwig. "Comparison of different extraction concept for the recovery of uranium from seawater." International Meeting on Uranium Recovery from Seawater (IMRUS-83). Atomic Energy Society of Japan, 1983. 34-50.

Borzekowski, J., M.J. Driscoll, and F.R. Best. Uranium from Seawater Rsearch: Final Progress Report, FY 1982. Department of Nuclear Engineering, Massachusetts Institute of Technology, Cambridge: Energy Laboratory, 1982.

Cochran, T., et al. Fast Breeder Reactor Programs: History and Status. International Panel on Fissile Materials , 2010.

Davies, R.V. et al. "Extraction of Uranium from Seawater." Nature 203, no. 4950 (1964): 1110-1115.

Driscoll, M.J. "Recent work at MIT on uranium recovery from Seawater." International Meeting on Uranium Recovery from Seawater. Atomic Energy Society of Japan, 1983. 1-11.

Forberg, S., G. Lagstrom, and P. Valla. "Recovery of Uranium from Seawater Using An Appraisal from Novel Sorbent Data." IMRUS 83: International Meeting on Recovery of Uranium from Seawater. 1983.

Gupta, Chiranjib, and Harvinderpal Singh. Uranium Resource Processing: Secondary Resources. Berlin and Heidelberg: Springer-Verlag, 2003.

Heal, G. "The Relationship between Price and Extraction Cost for a Resource with a Backstop Technology." Bell Journal of Economics, 1976.

Kanno, M. "Present Status of Study on Extraction of Uranium from Sea Water." Journal of Nuclear Science and Technology, no. 21 (1984): 1-9.

Kanno, M. "Design and Cost Studies on the Extraction of Uranium from Seawater." Separations Science and Technology 16, no. 9 (1981): 999-1018.

Kim, J., Tsouris, C., Oyola, Y., Janke, C. J., Mayes, R. T., Dai, S., Gill, G., Kuo, L., Wood, J., Choe, K., Schneider, E. A. and H. Lindner, "Uptake of Uranium from Seawater by Amidoxime-Based Polymeric Adsorbent: Field Experiments, Modeling, and Updated Economic Assessment." Industrial and Engineering Chemistry Research. 53, no. 14 (2014): 6076-6083.

Kim, J., Oyola, Y., Saito, T., Mayes, R., Janke, C., Dai, S., Tsouris, C., Schneider, E. A. and D. Sachde, "Recovery of Uranium From Seawater: a Review of current Status and Future Research Needs" Separation Science and Technology. 48, no. 3. (2013): 367-387.

Mayes, Richard, interview by Harry Lindner. Conversation with Richard Mayes (2012). 
Nobukawa, H., et al. "Development of Floating Type-Extraction System of Uranium from Sea Water Using Sea Current and Wave Power." Journal of the Society of Naval Architects of Japan, 1990: 319 - 328.

Nobukawa, H., M. Kitamura, S. Swilem, and K. Ishibashi. "Development of a FloatingType System for Uranium Extraction from Seawater Using Sea Current and Wave Power." Proceddings of the Fourth (1994) International Offshore and Polar Engineering Conference. The International Society of Offshore and Polar Engineers, 1994.

Nobukawa, H., M. Tamehiro, M. Kobayashi, H. Nakagawa, J. Sakakibara, and N. Takagi. "Development of Floating Type-Extraction System of Uranium from Sea Water Using Sea Water Current and Wave Power." Journal of the Society of Naval Architects of Japan, 1989: 281 - 292.

OECD Nuclear Energy Agency and the International Atomic Energy Agency. Uranium 2011: Resources, Production, and Demand. OECD, 2012.

Sachde, Darshan Jitendra. Uranium Extraction from Seawater: An Assessment of Cost, Uncertainty and Policy Implications. University of Texas at Austin, 2011.

Schneider, E., and D. Sachde. "Cost and Uncertainty Analysis of an Adsorbent Braid System for Uranium Recovery from Seawater." 2011.

Schneider, E., and D. Sachde. "The Cost of Recovering Uranium from Seawater by a Braided Polymer Adsorbent System." Science \& Global Security: The Technical Basis for Arms Control, Disarmament, and Nonproliferation Initiatives, 2013: 134-163.

Schneider, E., and H. Lindner. "Updates to the Estimated Cost of Uranium Recovery from Seawater." Pacific Basin Nuclear Conference (PBNC-2014). Vancouver, BC, Canada, 2014.

Schneider, E., and H. Lindner. Uranium Recovery from Seawater: Cost Analysis Updates. Technical Report, University of Texas at Austin, U.S. Department of Energy subcontract 00114954, 2012.

Sekiguchi, K., K. Saito, S. Konishi, S. Furusaki, T Sugo, and H. Nobukawa. "Effect of Seawater Temperature on Uranium Recovery from Seawater." Industrial \& Engineering Chemistry Research, 1994: 662-666.

Sugo, Takanobu, et al. "Recovery System for Uranium from Seawater with Fibrous Adsorbent and Its Preliminary Cost Estimation." Journal of the Atomic Energy Society of Japan, 2001: 1010-1016.

Tamada. "Current status of technology for collection of uranium from seawater." Erice Seminar, Japan Atomic Energy Agency, 2009.

Tamada, M., N. Seko, N. Kasai, and T Shimizu. "Cost Estimation of Uranium Recovery from Seawater with System of Braid Type Adsorbent." Transactions of the Atomic Energy Society of Japan, 2006: 358-363.

Tamada, Masao, Noriaki Seko, Noburu Kasai, and Takao Shimizu. "Cost Estimation of Uranium Recovery from Seawater with System of Braid Type Adsorbent." Transactions of the Atomic Energy Society of Japan, 2006: 358-363. 
Tsouris, C., J. Kim, Y. Y. Oyola, R. Mayes, C. Janke, and Dai, S. "Laboratory and Field Testing of Uranium Uptake from Seawater: Progress Report on First Year's Experiments." Oak Ridge National Laboratory, U.S. Department of Energy, Fuel Cycle Research \& Development, FCRD-RES-2012-000175, 2012.

Turekian, Karl. Oceans. Prentice-Hall, 1968.

U.S. Bureau of Labor Statistics. CPI Inflation Calculator. 2014. http://data.bls.gov/cgibin/cpicalc.pl? cost $1=11 \&$ year $1=1964 \& y e a r 2=2010$.

Varela, J. Mass and Momentum Transfer in Uranium-from-Seawater Sorption. SM Thesis, MIT Nuclear Engineering Dept., 1983.

Yamashita, H, Y Ozawa, F Nakajima, and T Murata. "The Collection of Uranium from Sea Water with Hydrous Metal Oxide. II. The Mechanism of Uranium Adsorption on Hydrous Titanium(IV) Oxide." 1980. 